\title{
MECHANISMS OF EXCITATION AND INHIBITION \\ IN THE NIGROSTRIATAL SYSTEM
}

by

THOMAS I. RICHARDSON

B.Sc. University of British Columbia, 1974

A THESIS SUBMITTED IN PARTAL FULFILLMENT OF THE REQUIREMENTS FOR THE DEGREE OP

MASTER OF SCIENCE

in

Faculty of Graduate studies

(Department of Physiology)

we accept this thesis as conforming

to the required standard

THE UNIVERSITY OF BRITISH COLUHBIA

MaY, 1979

(C) Thomas L. Richardson 
In presenting this thesis in partial fulfilment of the requirements for an advanced degree at the University of British Columbia, I agree that the Library shall make it freely available for reference and study. I further agree that permission for extensive copying of this thesis for scholarly purposes may be granted by the Head of my Department or by his representatives. It is understood that copying or publication of this thesis for financial gain shall not be allowed without my written permission.

Department of Physiology

The University of British Columbia 2075 Wesbrook Place Vancouver, Canada V6T IW5

Date May 25, 1979 


\section{$\underline{\text { ABSTRACT }}$}

The extracellular responses of neurons in the corpus striatum following single pulse stimulation of the substantia nigra or dorsal raphe nucleus were investigated in urethane anaesthetized rats. Nigral stimulation at low intensities $(10 \quad v)$ evoked single large amplitude spikes while higher intensities (10 to $20 \mathrm{v}$ ) evoked, in addition, a high frequency burst of small amplitude spikes or waves. spontaneous large spikes, or those induced by the administration of glutamate, were inhibited by nigral stimulation. The onset of inhibition coincided with the onset of the burst. If the burst was prevented, inhibition no longer occurred. Neither the inhibitory nor the burst response evoked by nigral stimulation was influenced by iontophoretically or systemically administered antagonists of dopamine or by chemical lesions of the dopaminergic neurons of the nigrostriatal pathway. However the excitation of large units by nigral stimulation was reversibly blocked by dopamine antagonists.

Stimulation of the dorsal raphe nucleus produced inhibition of spontaneously active striatal neurons. No excitatory response was ever observed. HRP injected into the striatum was transported to cells in the dorsal raphe nucleus and injection of tritiated leucine into the dorsal raphe nucleus produced significant transport of radio labelled protein to the caudate nucleus.

It is concluded that the burst response is produced 
by excitation of striatal interneurons through collaterals of the striatonigral pathway wh are intrinsic to the nucleus. Nigral stimulation causes an antidromic activation of the axon and a subsequent orthodromic activation of its collaterals. The interneurons activated by this "axon reflex" are inhibitory in function. It is further concluded that the dopaminergic neurons of the nigrostriatal tract make excitatory synaptic contact with striatal neurons in the central region of the nucleus. At least some of these target neurons project, in turn, to the globus pallidus. 


\section{TABLE $Q$ F CONTENTS}

Acknowledgements $\ldots \ldots \ldots \ldots \ldots \ldots \ldots \ldots \ldots \ldots \ldots . . \ldots$ vii

Table of Abbrevations ....................

Abstract. ............................ ii

Introduction $\ldots \ldots \ldots \ldots \ldots \ldots \ldots \ldots \ldots \ldots \ldots \ldots \ldots \ldots \ldots \ldots \ldots \ldots$

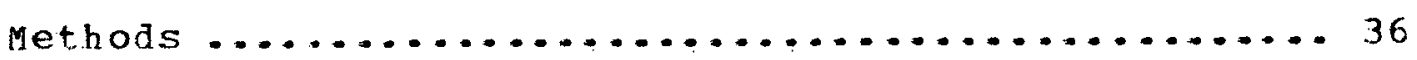

Surgical preparation $\ldots \ldots \ldots \ldots \ldots \ldots \ldots \ldots \ldots \ldots \ldots . \ldots$

stimulation procedure ................... 37

Microelectrode peparation ................. 37

Recording Procedures And Data Analysis ......... 38

Histology .......................... 40

Lesioning And Assay Procedures .............. 41

Results .......................... 43

Burst Response ....................... 43

Single onits ......................... 51

Antidromic Potentials ....................... 60

Lesioned Preparations ..................... 62

Actions of Pharmacological Agents ........... 66

Anatomical studies ....................... 69

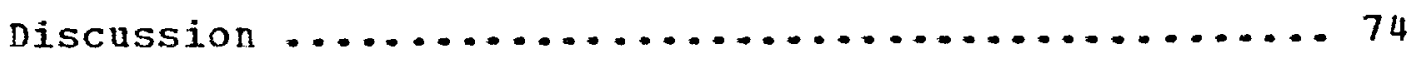

Burst Response ........................ 74

Pathway Mediating The Burst Response .......... 77

Inhibitory Response $\ldots \ldots \ldots \ldots \ldots \ldots \ldots \ldots \ldots \ldots \ldots . . \ldots 2$

Large Amplitude Cells $\ldots \ldots \ldots \ldots \ldots \ldots \ldots \ldots \ldots \ldots \ldots .65$

Conclusion $\ldots \ldots \ldots \ldots \ldots \ldots \ldots \ldots \ldots \ldots \ldots \ldots . . . \ldots 6$

References $. . \ldots \ldots \ldots \ldots \ldots \ldots \ldots \ldots \ldots \ldots \ldots \ldots . \ldots . \ldots 9$ 


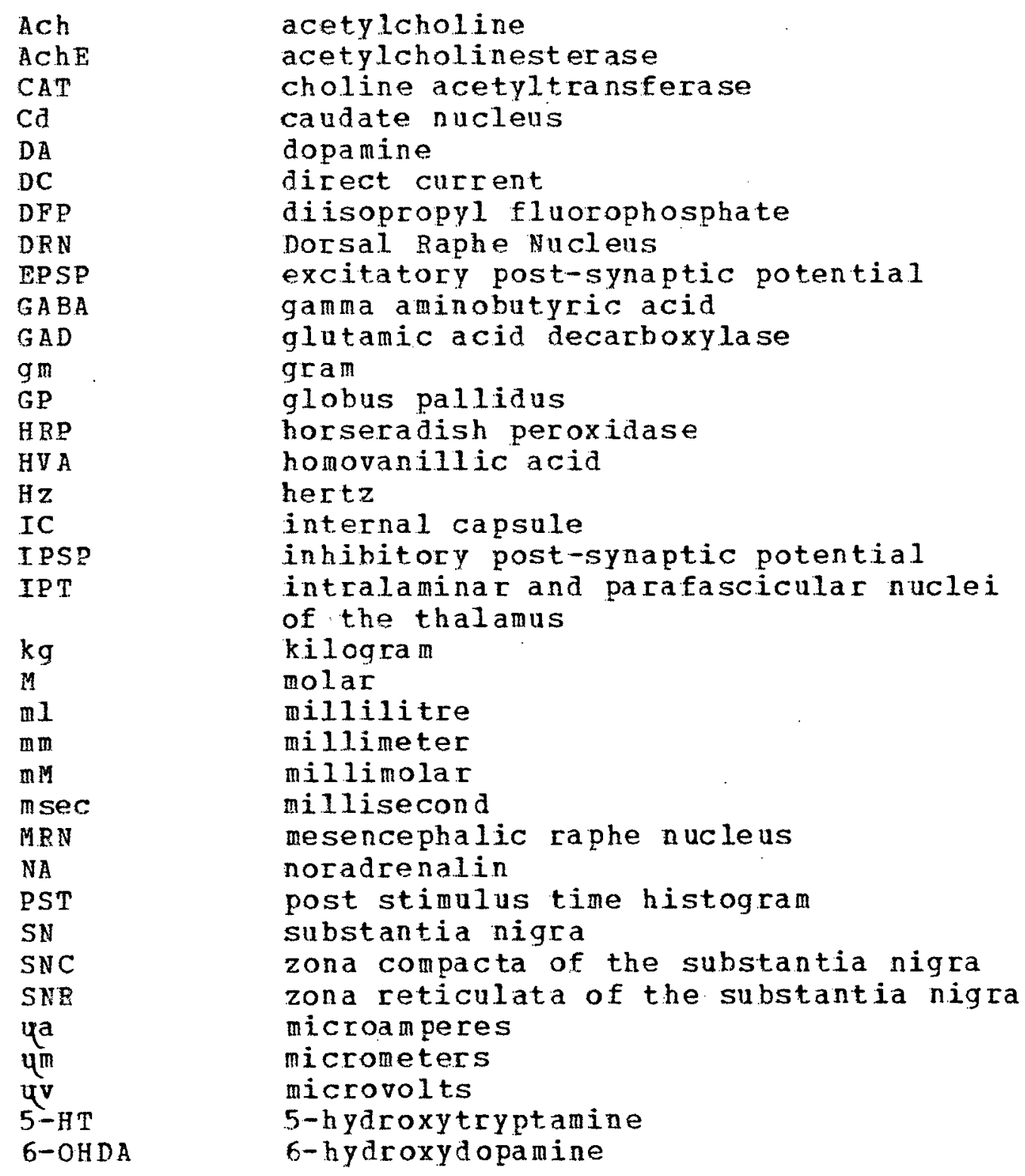




\section{IABLE OF FIGURES}

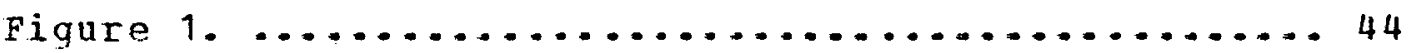

Figure $2 . \ldots \ldots \ldots \ldots \ldots \ldots \ldots \ldots \ldots \ldots \ldots \ldots \ldots \ldots \ldots, 45$

Figure $3 . \ldots \ldots \ldots \ldots \ldots \ldots \ldots \ldots \ldots \ldots \ldots \ldots \ldots \ldots, 47$

Figure $4 . \ldots \ldots \ldots \ldots \ldots \ldots \ldots \ldots \ldots \ldots \ldots \ldots \ldots \ldots, 48$

Figure $5 . \ldots \ldots \ldots \ldots \ldots \ldots \ldots \ldots \ldots \ldots \ldots \ldots \ldots \ldots . \ldots . \ldots$

Figure $6 . \ldots \ldots \ldots \ldots \ldots \ldots \ldots \ldots \ldots \ldots, \ldots \ldots \ldots \ldots \ldots ., 51$

Figure $7 . \ldots \ldots \ldots \ldots \ldots \ldots \ldots \ldots \ldots \ldots \ldots \ldots \ldots \ldots \ldots, 52$

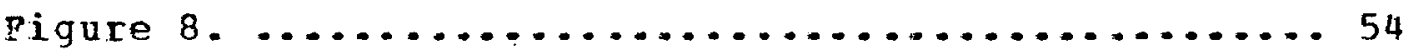

Figure 9. $\ldots \ldots \ldots \ldots \ldots \ldots \ldots \ldots \ldots \ldots \ldots \ldots \ldots \ldots \ldots \ldots$

Figure $10 . \ldots \ldots \ldots \ldots \ldots \ldots \ldots \ldots \ldots \ldots \ldots \ldots \ldots \ldots \ldots \ldots$

Pigure $11 . \ldots \ldots \ldots \ldots \ldots \ldots \ldots \ldots \ldots \ldots \ldots \ldots \ldots \ldots \ldots . \ldots \ldots$

Figure $12, \ldots \ldots \ldots \ldots \ldots \ldots \ldots \ldots \ldots \ldots \ldots \ldots \ldots \ldots, 61$

Figure 13. ................................. 63

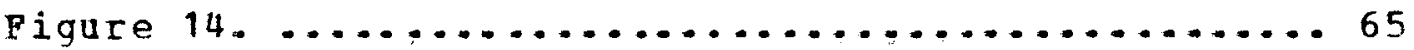

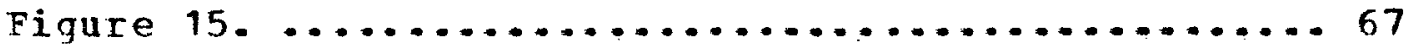

Figure $16 . \ldots \ldots \ldots \ldots \ldots \ldots \ldots \ldots \ldots \ldots \ldots \ldots \ldots \ldots \ldots$

Figure $17 \ldots \ldots \ldots \ldots \ldots \ldots \ldots \ldots \ldots \ldots \ldots \ldots \ldots \ldots . . \ldots \ldots$

Figure $18 . \ldots \ldots \ldots \ldots \ldots \ldots \ldots \ldots \ldots \ldots \ldots \ldots \ldots \ldots \ldots .71$

Figure 19. $\ldots \ldots \ldots \ldots \ldots \ldots \ldots \ldots \ldots \ldots \ldots \ldots \ldots \ldots, 88$ 


\section{ACEKNOWLEDGEMENTS}

It is my fleasure to thank Dr. H. Mclennan and Dr.J.J. Miller for their supervision, teaching and continued interest in this project.

I would also like to thank Yvonne Heap and Ron Walker for their technical assistance, Helen Brandís for assistance in preparation of the HRP histology and Dr. C. Fibiger and associates for performing the catecholamine and tritiated protein assays. Finally I would like to thank Joanne, my wife, for continued patience and assistance in bringing this effort to completion. 
$1-4$

LEAVES 1 - 4 OMITTED IN PAGE NUMBERING 


\section{IN $\mathbb{T}$ RODOUCTION}

The early anatomists defined the extrapyramidal motor system as all central motor mechanisms not mediated through the pyramidal tracts (Jung and Hassler, 1960). However this definition has led to difficulties. Areas of the cerebral cortex classically defined as extrapyramidal in function have been shown to contribute a significant number of fibres to the pyramidal tracts, while the pyramidal cortex, area 4 gamma, has a major projection terminating in subcortical extrapyramidal structures (Carman et al, 1963; Russell and Demyer, 1961). Thus every cortical motor area has both pyramidal and extrapyramidal functions. Furthermore, since lower vertebrates do not have a pyramidal tract their entire motor system is, of necessity, extrapyramidal.

More recently a functionally relevant concept of extrapyramidal motor mechanisms has developed based mainly on clinico-pathological studies in man. A group of related syndromes, referred to as extrapyramidal motor diseases, result from lesions of the caudate- putamen (cd), globus pallidus (GP), subthalamic nucleus and substantia nigra (SN) (Vogt and Vogt, 1920; Wilson, 1912; Tretiakoff, 1919). Each disease involves an abnormality of unconscious or stereotyped motor behavior. The hyperkinetic syndromes are characterized by an excess of spontaneous, aimless and involuntary movements. These syndromes include chorea, resulting from loss of small cells in the Cd and GP; 
athetosis, resulting from lesions damaging the large cells of these nuclei and ballismus, resulting from lesions of the subthalamic nucleus. The hypokinesis of Parkinson's disease is characterized by an absence of spontaneous reactive and automatic movements as well as a persistent increase in muscle tone without spastic paresis or essential changes in spinal reflexes. This syndrome is associated with cell loss in the pars compacta of the $\mathrm{SN}$. on the basis of these syndromes the term extrapyramidal motor system is now used to refer to the motor nuclei and cortical regions involved in the integration and regulation of unconscious and stereotyped motor behavior.

The neuronal circuitry of the extrapyramidal motor system is complex and not yet fully understood. Howerer. by considering only the major and well established fibre systems, certain organizational patterns are evident. The extrapyramidal nuclei are under the influence of motor as weil as sensory afferents mainly via cortical and thalamic projections to the cd. This nucleus receives a somatotopically organized projection from all regions of the ipsilateral cerebral cortex (Carman et al, 1963) as well as from the supplementary motor area and area 5 of the contralateral cortex (Carman et al, 1965). The heaviest projection occurs from the ipsilateral somatosensory and motor regions. The intralaminar nuclei of the thalamus (I.P.T.), including the parafascicular and centromedian nuclei, have a major projection terminating in the insilateral cd (Powell and Covan, 1956). These 
nuclei receive sensory afferents from spinal and reticular origins and are also strongly influenced by activity in the motor cortex. The cd receives additional afferents from other extrapyramidal motor nuclei. The most extensively studied of these originates in the SN (Anden et $a 1,1966)$.

Efferent fibres of the cd are thought to terminate almost exclusively in the $\mathrm{SN}$ and globus pallidus (Nauta and Mehler, 1966; Szabo, 1967). Both projections are somatotopically well organized. The smaller projection is to the $\mathrm{SN}$, the pallidal projection is the major outflow from the cd.

The GP, unlike the cd, does not receive afferents from either cortical or thalamic sources. The striatopallidal projection is its primary input although the $\mathrm{SN}$ and subthalamic nucleus also contribute fibres (Carpenter and Strominger, 1967).

The efferent projections from the two segments of the GP differ. The external segment projects to the subthalamic nucleus while the internal segment projects to the $S N$, midbrain tegmentum and the thalamus (Nauta and Mehler, 1966; Carpenter and Strominger, 1967; Ranson and Ranson, 1942). Thus both the SN and subthalamic nucleus have reciprocal connections with the GP. The thalamic projections terminate in the ventral anterior and ventrolateral nuclei as well as the centromedian nucleus of the intralaminar group. The thalamic motor nuclei, ventral 
anterior and ventro-lateral, project in turn to the motor cortex completing a neuronal loop from the cortex through the Cd, GP, thalamus and back to the cortex. The centromedian nucleus, since it has both efferents to and afferents from extrapyramidal nuclei, is part of a second loop involving a pathway from the centromedian through the Cd, GP and back to the centromedian.

Modifications of motor behavior by the extrapyramidal system results largely through thalamic relays to the motor cortex. However, before extrapyramidal influences reach the cortex they are integrated, in the thalamic nuclei, with influences from other central motor and sensory mechanisms. The ventral anterior and ventrolateral nuclei, both thalamic motor structures, are sites for convergence of cerebellar activity via dentato- and rubro-thalamic fibres and extrapyramidal activity via the pallido-thalamic projection. The activity of the ventral anterior and ventral lateral nuclei can then influence the motor cortex through a direct thalamo-cortical pathway. The centromedian nucleus receives extrapyramidal afferents from the GP and sensory afferents from spinal and reticular origins. Descending influences from the motor cortex are also present. Although the major projection of the centromedian nucleus is to the cd providing a feedback to the extrapyramidal system, its activity is known to influence the cortex via intrinsic projections to the other thalamic nuclei (Purpura and Yahr, 1966). 
Extrapyramidal influences on the motor cortex are likely to result in modification of activity descending to spinal levels in the pyramidal tracts. projections to the midbrain tegmentum from the $S N$ and globus pallidus, and to the tectum from the $\mathrm{SN}$ may also have important influences on motor behavior since these midbrain regions are sources of major descending pathuys modifying the cutput of spinal motor neurons.

The integration and modification of activity in these various pathways is a result of the anatomical and functional organization of the neurons within the nuclei. However our understanding of the intrinsic organization of the motor nuclei is far from complete. The ca, the largest subcortical structure in the mamalian nervous system, and its associated nuclei, the $\mathrm{SN}$ and GP, have received the most thorough investigation.

Cajal and Ramon (1911) first investigated the cd with Golgi stains and the light microscope. More recent workers have expanded on Cajal's classical description of the neuronal organization and with the advent of the electron microscope have also investigated the synaptic organization of the nucleus. In view of this detailed anatomical data the structure of the cd can no longer be refered to as homogeneous. Although it is not organized into discrete lamina of specialized cells as is seen in cortical structures, the neurons are grouped into clusters of cell bodies surrounded by neuropil fkemp and powell, 
1971 a; Chronister et al, 1976). Furthermore the nucleus is traversed by fascicles of cortico-fugal fibres travelling towards the basis pedunculi. The distribution of these fibres differs in the striatum of various species. Man, with a well developed anterior limb of the internal capsule (IC), has a striatum almost devoid of large fascicles of passing fibres. In the cat the anterior limb of the IC is less well developed and many of the cortico-fugal fibres pass through the adjacent striatum. Hovever the rat has no anterior limb of the IC and the corresponding fibres pass through the substance of the striatum as large fascicles of axons 50 to 200 um in diameter. on coronal sections the fascicles are cut in cross section and appear to be surrounded by clusters of cells. Each cluster has $10-14$ cell bodies and is about 60 um across. Dendrites stream out from these clusters and form tight bundles interconnecting the cell clusters and surrounding the fascicle (Chronister et al, 1976). In sagital or frontal sections the fascicles run with the plane of the section in a radial fashion from the IC to the cortex. clusters of cell bodies form columis of cells parallel to the fascicles. Tight bundles of dendrites are seen passing across the fascicles joining cell groups on its two sides.

Kemp and powell (1971 A, B, C) have found that the neurons of the cd can be divided into at least six different varieties based on morphological characteristics. These neurons form two functional groups, 
interneurons and projecting neurons.

The vast majority of cd neurons, over 96\%, are interneurons. At least $35 \%$ of these are medium sized spiny cells. The somata are 12-14 $4^{\mathrm{m}}$ across with branched dendrites forming a spherical arborization extending 1802404 m awa from the parent cell. Although the primary dendrite is smooth its branches are studded with tightly packed spinous processes. The axons in some examples may travel long distances however most have multiple collaterals terminating within the dendritic tree of the parent cell.

The remaining $5 \%$ of interneurons can be divided into three varieties. The first group also consists of neurons with cell bodies of medium size. However, their dendrites are long and slender, often exceeding 300 um in length. only occasional spinous processes are present. The axon often bifurcates and the collaterals usually terminate within the dendritic tree of the parent cell. The second variety has medium sized cell bodies which give rise to spineless dendrites with multiple varicosed and twisted branches. The dendrites form a dense arborization surrounding the parent cell. The short axons have multiple bifurcations which usually terminate near the cell body. The last variety consists of interneurons with smal1 cell bodies 5-9 ym across and very dense dendritic networks within 50-60 $q^{m}$ of the soma. No axons have been identified. 
No specificity between afferent systems and cell groups was detected by Kemp and powell. Each variety of interneuron receives synaptic contacts en passent from afferent fibres of the cortex, thalamus and SN. The majority are axospinous but axodendritic and axosomatic contacts are also present. The majority of afferent terminals are 1 um in diameter but a few are 5 ym across. The terminals contain many round vesicles and the synapses have asymmetrical specialization of the pre and post synaptic membrane. They are described as Golgi type 1 synapses (Gray, 1959). The interneurons also receive mainly axodendritic and axosomatic synapses from other interneurons. Most of these terminals have flattened pleomorphic vesicles and symmetrical specialization of the pre and post synaptic membrane. They are described as Golgi type 2 synapses. The majority of interneurons influence cells within a radius of $450 \mathrm{y}^{\mathrm{m}}$.

The second functional group of neurons project beyond the cd to other structures. They form a small group of cells amounting to only $3-4 \%$ of the total number of neurons. Two morphological varieties found in approximately the same proportion are described by kemp and powell. The medium sized projecting neurons have thick dendrites studded with only a few spines. The axons are varicosed and occasionally give off collaterals. However they do not form a profuse network. Similar cells were said to project beyond the nucleus by cajal and Ramon 
(1911). The second variety consists of very large fusiform ce11s 20-30 um in length. They have long straight dendrites often extending as far as a millimeter beyond the parent cel1. The dendrites have a few spinous processes along their length. The axons are very long and have few collaterals. Kemp and powell refer to these neurons as "giant cells".

Axons from the cortex, thalamus and SN form Golgi type 1 synapses with the spines and dendrites of projecting neurons. However the interneurons make Golgi type 2 synaptic contact with their dendrites, somata and intial segments.

The projecting neurons of the cd send axons to the GP and SN. The striato-pallidal fibres pass directly to the adjacent GP and terminate with axodendritic synapses. Both Golgi type 1 and 2 synaptic specializations are present. The striato-nigral fibres must first pass through the GP and then travel in the IC and basis pedunculi. As they approach the $S N$ the fibres move laterally and pass dorsally into the ventral aspect of the pars reticulata of the SN. Here they synapse on the dendrites of the reticulata cells. Again, both Golgi type 1 and 2 synapses are seen.

In an attempt to elucidate the functions of the extra pyramidal motor nuclei early investigators cbserved the behavior resulting from stimulation and lesioning of these structures. Ferrier (1873) found that faradic stimulation 
of the cd caused pronounced bending of the head and body to the contralateral side. However these movements were thought to result from unintentional stimulation of nearby capsular fibres since movements were not cbserved in animals with degeneration of the IC. Furthermore, Wilson (1914) was unable to denonstrate any effect of faradic stimulation of the putamen in monkeys. On this basis he considered the putamen an inexcitable structure. However later studies, using more discrete stimulation techniques report three general patterns of behavioral response each dependent on the frequency of ca stimulation.

Low frequency $(0.2$ to $10 \mathrm{~Hz})$ bilateral stimulation of the cd for long periods of time may produce in the unanaesthetized freely moving cat what Hess (1948) describes as partial sleep (Parneggiani, 1962). This state is characterized by inactivity with little spontaneous movement and a deficient motor responsiveness to external stimulation. Heath and Hodes (1952) have also reported sleep following stimulation of the $c d$ in monkey and man. However, these findings have not been confirmed by Mclennan et al (1964). The latter investigators detected neither sleep nor decreased alertness even in an environment most conducive to sleep. In fact, an increased alertness was invariably observed.

Bilateral stimulation of the $c d$ at higher frequencies $(10$ to $30 \mathrm{HZ}$ ) causes an arrest reaction (Jung and Hassler, 1960; McLennan et al, 1964) similar to that described by 
Hunter and Jasper following stimulation of the intralaminar thalamic nuclei (Hunter and Jasper, 1949). ongoing behavior of the cat, such as walking towards a dish of food, will come to a sudden halt at the onset of stimulation, even though the animal remains alert. Following cessation of the stimulation the cat will resume its original behavior. Similarly intermediate frequencies of cd stimulation increase reaction time by several hundred percent for performance of a well learned visual discrimination task. However, when the response is initiated it is excecuted smoothly and rapidy. Buchuald (Buchwald et al, 1961 a) believes that the stimulation interferes with the initiation of the behavior rather than its subsequent performance.

Unilateral stimulation of the $\mathrm{cd}$ at intermediate frequencies produces an apparently purposeful turning of the head and body to the contralateral side. The turning movement often develops into a well coordinated rotation of the animal in a direction contralateral to the site of stimulation. The body regions affected are somatotopically related to the site of stimulation within the cd Forman and Mard, 1957). Ventral sites are associated with movements of the head, neck and forelimbs wereas dorsal sites are associated with movements of the trunk and hindimbs. Forman and rard claim these contraversive movements are independent of cortico-spinal systems. They found that motor responses to cortical stimulation of anaesthetized cats are not influenced by simultaneous 
stimulation of the cd. On the other hand Hendley and Hodes (1953) demonstrated that turning movements are dependent on intact connections between the cd and medial SN.

Stimulation of the cd at a high frequency $(100$ to 300 Hz) results in behavioral arousal or an alerting response in drowsy animals (Buchwald and Wyers, 1961 b); a response similar to that seen following stimulation of the reticular formation. If the stimulus is continued for a few seconds a tremor of the contralateral fore or hindlimb will be induced.

More recently workers have studied the neurochemical properties of the extra pyramidal motor system. Analysis of the $C d, G P$ and $S N$ has revealed significant concentrations of several putative synaptic transmitters. The presence of acetylcholine (Ach), 5-hydroxytryptamine (5-HT) and dopamine (DA) suggests that they may function as transmitters either in pathways interconnecting extrapyramidal structures or in the intrinsic circuitry of the nuclei. Rowever to demonstrate that a substance functions as a transmitter is a difficult task. A number of criteria must be fullfilled. These vere first formulated during investigation of the peripheral autonomic nervous system. It must be demonstrated that 1) the substance is present in the terminals, 2) the neuron contains the appropriate precursors and enzymes necessary for synthesis of the substance, 3) the substance is released upon stimulation of the neuron, 4) the substance 
when applied artificially to the synapse, mimics the response seen following stimulation of the neuron, and 5) that a mechanism for inactivation of the substance is present at the synapse (Florey, 1960).

Although $A C h$ is clearly established as a synaptic transmitter in the periphery its role in the CNS is less well defined. The highest concentration of Ach, choline acetyltransferase (CAT) and acetylcholine esterase (AChE) in the brain are found in the cd although considerable quantities are also found in the GP and SN. CAT is the synthetic enzyme required for conversion of choline to Ach. Therefore it must be present in cholinergic neurons. However AchE, the catabolic enzyme required for inactivation of Ach at the synapse may be present in either cholinergic neurons or neurons receiving a cholinergic input. Investigation of the role of Ach in the basal ganglia is based mainly on localization of CAT and AchE since Ach is very labile in brain tissue. Subcellular fractionation of striatal tissue shows that most of the CAT is concentrated in nerve endings while a large portion of AchE is membrane bound.

Sternberger (1970) developed a very sensitive immunohistochemical technique for localizing tissue enzymes. Using a complex sandwich of immunoglobulins, peroxidase is bound to the enzyme and a brown reaction product results following addition of bydrogen peroxide and diaminobenzidine. Using this marker, Hattori et al 
$(1976$ B) bave identified a population of medium sized (7$14 \mathrm{um}$ ) CAT containing neurons distributed in large numbers throughout the cd the electron microscope reveals CAT containing dendritic processes receiving asymmetrical axospinous synapses mainly from CAT free terminals. Terminals containing CAT make similar synapses with CAT. free dendrites. The axons of CAT containing cells a re not we 11 visualized with this technique and little direct evidence exists to determine if the axons all remain within the cd or if some form the efferent projections of the nucleus. However MCGeer et al (1971) believe that CAT cells are cholinergic interneurons completely intrinsic to the nucleus. They found that electrolytic lesions of the cd did not influence CAT or AchE levels in regions which receive major striatal efferents including the thalamus, GP and midbrain (mcGeer et a 1, 1969). They reasoned that if CAT in the $G P$ and $S N$ is present in terminals of striatal efferents, lesions to the cd should have caused a significant drop in CAT concentration in these structures. However, interpretation of their negative results must be made with caution. If the target nucleus also contains CAT in cell bodies as well as terminals from other nuclei, the change in cam level following cd lesions may be undetectable. McGeer et al (1971) also demonstrated that lesions of the cortex, thalamus, ventral tegmentum and $G P$ do not influence CAT or AchE levels in the $\mathrm{cd}$. They reasoned that, if cholinergic neurons project beyond the striatum, lesions of the target nuclei should have caused 
retrograde degeneration of efferent neurons and a subsequent decrease in CAT levels in the striatum. However, if the cholinergic neurons have multiple collaterals with the majority synapsing within the nucleus and only a few projecting to other brain regions, retrograde degeneration of the somata and intrinsic collaterals would not be expected.

The cellular localization of AchE is easily examined in routinely fixed tissue since the enzyme retains activity even after exposure to formaldehyde. When brain tissue is incubated with acetylthiocholine, an Ach analogue, AchE will result in the production of an opaque precipitate. Examination of the tissue vith the light microscope will then reveal sites of high enzyme concentration. When this technique is applied to the adult striatum a dense staining occurs throughout the nucleus and detailed cellular localization is impossible. clearly. Ache is present in high concentration in the majority of cell bodies and processes. However in the newbcrn rat very little AchE activity is present in the striatum. Butcher Hodge (1976) studied the subsequent development of AchE staining during mataration of the cd and $S N$. During the first 3-10 days of life, islands of AchE activity appear in the lateral regions of the cd. Clusters of AchE containing cell bodies and their processes are often observed within these islands. The neurons have multipolar somata and are usually triangular or fusiform in shape, with the majority from $18-20$ um in diameter. Although 
slightly larger than the medium sized cells described by Kemp and powe11, Butcher believes that on the basis of their morphology and frequent occurrence these neurons should still be considered within the medium sized group. They may be either the medium projecting neurons or the medium smooth interneurons. Occasionally AchE neurons with very large fusiform somata and prominent cellular processes are detected. They correspond to the $1 \%$ of cd neurons classified as giant cells by Remp and Powell. The long thick axons of giant cells are believed to project beyond the nucleus. After 10 days of life an increasing number of cellular processes become positive for AchE until at 15 days it is not possible to identify individual cell bodies. The loss of distinct staining of neurons appears to be a function both of a diffuse staining of a multitude of cellular processes as well as a lover intensity of staining in the somata. This suggests that AchE is synthesized in the somata at high rates until adequate concentrations are available in the more distal regions of the cell. At that time the rate of synthesis decreases and as a result AchE concentration in the cell body also decreases. However Butcher Hodge (1976) found that treatment of the neostriatum of the adult rat with diisopropyl fluorophosphate (DFP), a potent irreversible AchE inhibitor will induce synthesis of new enzyme. In this way the cellular localization of AchE can be studied in the adult. Immediately after a local injection of DFP into the $c d$ a region $2 \mathrm{~mm}$ in diameter at the injection 
site is devoid of AchE staining. However by 10 hours after the injection cell bodies and some processes are clearly stained. These cells have the same characteristics as those found in the neonate. Systemic injection of DFP causes a temporary loss of AchE activity throughout the striatum. Although the detailed characteristics of AchE cells are not seen with this technique distribution of the cells can be investigated. Butcher et al found the AchE cell dispersed throughout the nucleus with a pronounced tendency toward clustering in the immediate vicinity of the fascicles traversing the nucleus.

In the SN of the rat AChE staining is more intense in the pars compacta than the pars reticulata at all stages from neonate to adult. In the neonate AchE staining is diffusely present throughout the compacta. However in the pars reticulata discrete somata $8-40$ ym in diameter, as well as bundles of fibres, are deeply stained from day 315. Later these cells and fibres become less visible against a background of AchE staining. However in the adult rat treated with DFP no AchE cells are observed in the pars reticulata. Instead, intense staining of the pars compacta neurons is observed (Butcher and Bilezikjian, 1975). Since the compacta neurons are believed to be dopaminergic in function the AchE synthesized by these cells may serve to inactivate Ach released from cholinergic afferents. This finding also serves to point out that neurons rich in AchE need not be cholinergic in function. 
A cholinesterasic striato-nigral pathway has been described by olivier et al (1970). They found AchE staining of fibres following the same anatomical route as the striato-nigral pathway demonstrated by silver impregnation (Voneida, 1960). Electolytic lesions of the cd resulted in a loss of staining for AchE along the pathway although lesions of the $S N$ were without effect. olivier suggested that the striato-nigral pathway is cholinergic since fibres following the appropriate route are rich in AchE and both the $C d$ and the $S N$ contain high concentrations of Ach. Hovever his conclusion must be reassessed in light of the recent demonstration of AchE staining in dopaminergic neurons of the nigrostriatal path way.

The putative transmitter $5-\mathrm{HT}$ is, also present in relatively high concentration in the cd (Anden et al, 1966; Bogdanski et al, 1957; Broch and Marsden 1972). The terminals $\mathrm{rich}$ in $5-\mathrm{H} \mathrm{T}$ found in forebrain regions are derived exclusively from cell bodies located in the mesencephalic raphe nuclei (MRN) (Anden et al, 1966; Ungerstedt, 1971). Lesions of these nuclei, particularly the dorsal or median, or interruption of the projecting fibres at the level of the ventral tegmentum or medial forebrain bundle result in an extensive reduction of striatal 5-RT and its synthetic enzyme, tryptophan hydroxylase (Kostowski et al, 1968; Kuhar et a1, 1972; Poirier et al, 1967; Poirier et al, 1969). On the other 
hand, an increased release of 5-HT from the striatum follows stimulation of the raphe nuclei fHolman and Vogt, 1972). Nauta et al (1974) studied the distribution of labelled cell hodies folloving the injecticn of horse radish peroxidase (HRP) into the $C$. This protein is taken up by nerve terminals and transported in a retrograde direction to the cell body. He found labelled cells mainly in the cortex, thalamus, and the $\mathrm{SN}$. However he also noted some cells in the dorsal raphe nucleus (DRN). These data suggest the presence of a seritonergic pathway from the MRN to the striatum.

The $S N$ and GP contain the highest concentration of gama-aminobutyric acid (GABA) and its synthetic enzyme, glutamic acid decarboxylase (GAD), in the brain (Lowe et al. 1958; Baxter and Roberts, 1959; Fahn and Cote, 1968). The cd also contains appreciable concentraticns of both compounds but in only 30 to $50 \%$ the concentrations found in the GP and $S N$ (Enna et al, 1975). GABA has been clearly established as an inhibitory transmitter in purkinje cells of the cerebellum, however its role in the basal ganglia is less well defined. Electrolytic lesions of the GP or hemitransection of the brain at the level of the subthalamus result in an $80 \%$ decrease in GAD concentration in the ipsilateral SN (MCGeer et al, 1974). No change in GAD concentration is seen in the ipsilateral cd. Kim et al (1971) have reported that electrolytic lesions of the cd cause a $20 \%$ drop in levels of $G A B A$ in the $S N$. However more recently McGeer et al (1974) found that interruption of 
the striato-nigral pathway, by hemitransection of the hrain at the level of the anterior commissure, did not influence levels of GAD in the $S N$ in 11 of 14 animals. The remaining 4 animals had a reduction in GAD of $30 \%$. However these animals were noted to have additional damage to the GP. These findings suggest that the pallidonigral pathway may be GABAnergic in function. However, GABA is unlikely to function as the transmitter in the striato-nigral tract.

substance $P$, a polypeptide, is a putative neurotransmitter in the somato-sensory system at the spinal level (otsuka et al, 1975). However the SN contains the highest concentration of substance $p$ of any region of the spinal cord or brain /Kanazawa and Jessel 1976; Duffy et a 1 (1975) demonstrated that much of the substance $P$ is in synaptosomes. Lesions of the striato-nigral pathway lead to a shatp drop in levels of substance $p$ found in the SN (Kanazama and Jessel 1976). Immunohistochemical studies indicate that axons containing substance $p$ are found in the $5 N$, periagueductal grey matter, amygdala and thalamus. However only the habenular nucleus has been found to contain labelled cell bodies (Hockfelt et al, 1975).

$D A$ is found in higher concentration in the $C d$ and $S N$ than any other CNS structure. Its synthetic enzyme, 1-dopa decarboxylase, is also present in high levels (Bertler and Rosengren, 1959 a $\varepsilon$ b; Carlsson, 1959). In some brain regions, such as the hypothalamus. DA is a precursor for 
synthesis of noradrenaline (NA) and accounts for only about $10 \%$ of the total catecholamine content of the tissue. However in the basal ganglia Bertler and Rosenger $(1959$ A and $B)$ found $D A$ in 10 to 100 times the concentration of the NA. They suggested that DA has a function in the basal ganglia unique from its role as a synthetic precursor to NA.

Particular interest in the nigrostriatal projection was generated by the discovery that the DA content of the cd yas vastly depleted in brains studied at autopsy of patients suffering from idiopathic or postencephalitic Parkinson's disease (Ehringer and Hornykiewicz, 1960). It had been known previously that the neurons cf the pars compacta, the pigmented portion of the SN, undergoes an almost total degeneration in the disease (Tretiakoff, 1919). These findings suggested that the neurons of the pars compacta are rich in DA and that axonal and terminal degeneration of these cells results in a depletion of striatal dopamine in Parkinsonian patients. However it was first necessary to prove that the DA content of the striatum was specifically in terminals of $\mathrm{SN}$ neurons.

Laverty et al (1963) studied the DA in various subcellular fractions of homogenates of the dog cd. They found high concentrations of DA in the synaptosomal fraction and the soluble supernatant fraction. They suggested that $D A$ in the $c d$ is present in synaptic terminals in a free and easily releasable form, although 
the source of these terminals was unknown. Poirier and Sourkes (1965) found that a unilateral lesion of the $S N$ results in a greater than $50 \%$ depletion of DA in the ipsilateral ca. This finding demonstrated a direct influence of nigral efferents on the DA content of the striatum. Dahlstróm and Fuxe (1964), using the histofluorescence technique of Falck et al (1962), were able to demonstrate clearly the presence of dopamine in neurons of the nigrostriatal pathway. Attempts to identify the axons of the pathway by classical techniques had been met with frustration, although it was known that lesions of the cd caused retrograde degenerative changes in nigral cells. However later work by Shimizu and ohnishi (1973) using Fink-Heimer's modification of the Nauta method did clearly demonstrate the existence of this pathway.

The cells of origin of the nigrostriatal path way lie in the pars compacta of the SN. These large DA containing cells have extensive arborization of their dendrites. They penetrate at right angles through the pars reticulata and receive synaptic contact from reticulata cells. The pars reticulata is populated by smaller cells uith dendrites which arborize within the pars reticulata. Their axons synapse with dendrites of compacta neurons and also give rise to the nigropallidal and nigrotegmental pathways. The axons of compacta cells travel towards the ca first in the medial forebrain bunde and then in the medial aspect of the internal capsule. They are extremely fine unmyelinated axons with a relatively low dopamine content. They enter 
the ventro-medial aspect of the $c d$ after passing, at least in part, through the GP. In the cd the fibres branch extensively and are then distributed throughout the nucleus. Fach fibre has a multitude of varicosities, high in dopamine content, each one making a synaptic contact within the dendritic system of a cd neuron. In this way the axons from a relatively small number of $S N$ neurons are able to account for the very high content of dopamine in the striatum.

Portig and Vogt (1969) first investigated the release of dopamine in the striatum following activation of the SN. They measured the concentration of various compounds in a solution perfusing the lateral cerebral ventrical. Electrical stimulation of the $S N$ resulted in only an occasional rise in dopamine concentration in the solution. However since striatal dopamine is rapidly transformed enzymatically to homovanillic acid (HVA), dopamine released in the cd may be converted to Hy before reaching the surface of the nucleus. When HVA levels vere measured, SN stimulation for 3 or 4 minutes resulted in an increased concentration in the perfusate lasting over an hour.

Krnjević and phil1is (1963) examined the effects of DA applied iontophoretically to cortical neurons. By first applying glutamate they induced firing in otherwise silent units. They found that concurrent application of DA depressed the firing of these cells. In a second experiment peripheral stimulation was used to evoke a 
synaptic response. Iontophoretic application of DA completely blocked the evoked potentials.

Bloom et al (1965) studied the response of striatal neurons to iontophoretically applied DA. They found very large numbers of spontaneously active units in the ca of unanaesthetized cats. often several units were recorded simultaneously from one position of the recording electrode. Fifty percent of these cells showed a decrease in discharge rate following iontophoretic application of DA. However $14 \%$ had an increase in firing rate. Anaesthesia caused a significant change in the activity of striatal units. After administration of chloralose or barbiturate almost no spontaneous units could by detected. When the influence of iontophoretically applied DA was tested on glutamate induced activity, $60 \%$ of the units were depressed and only $2.5 \%$ showed a facilitation of their firing rate.

Herz and zieglgañ sberger (1968) also studied the effects of iontophoretically applied DA on striatal neurons. They confirmed that DA depresses the spontaneous or glutamate induced activity of the majority of neurons in the $c d$. Dopamine also blocked unit responses evoked by thalamic stimulation. However if a unit was depolarized by a high dose of glutamate, DA often caused the cell to return to a high frequency of firing. The authors suggested that DA may depress firing of most neurons by causing a hyperpolarization or repolarization of the 
membrane.

McLennan and York (1967) found that the activity of $60 \%$ of striatal neurons was depressed and the activity of 9\% was facilitated by iontophoretic application of DA. The effects of DA could be prevented by the previous iontophoretic administration of phenoxybenzamine, an alpha adrenergic blocker, but not by dichloroisopropylnoradrenaline, a beta blocker. Stimulation of the $S N$ was found to evoke either a single unit or a burst of action potentials with an average latency of 15 - $30 \mathrm{msec}$. Both responses mere depressed by iontophoretic application of DA. The depression was blocked by previous application of the alpha blocker. The alpha blocker alone did not influence the response. These findings suggested that DA may function as an inhibitory transmitter within the $C$. However if DA functions as a transmitter in the nigrostriatal pathway, stimulation of the SN and iontophoretic application of DA would be expected to influence striatal neurons in a similar manner. McLennan suggested that two classes of DA receptor may exist. The neurons excited by iontophoretic application of DA or nigral stimulation would have excitatory receptors and the $60 \%$ of neurons responding with a depression of spontaneous activity would have inhibitory receptors. However none of the neurons responding with an increased discharge rate to application of DA vere responsive to nigral stimulation. Furtbermore units evoked by nigral stimulation responded to 
application of DA with a decreased firing rate.

Connor (1970) studied the influence of nigral stimulation on spontaneous or glutamate induced activity of striatal neurons. Following the application of a train of 4 stimuli at 100 pulses per second to the $S N, 50 \%$ of striatal neurons responded with a decreased frequency of discharge lasting about $50 \mathrm{msec}$. Eighty percent of these neurons were also depressed by iontophoretic application of DA. The false transmitter, alpha-methyldopamine, blocked both the stimulus and DA induced depression of firing. On the other hand, for $20 \%$ of the neurons, nigral stimulation produced a facilitation of firing frequency lasting up to $40 \mathrm{msec}$. If glutamate application was stopped nigral stimulation often continued to evoke a single unit at a constant latency. The average latency for different units was $20 \mathrm{msec}$. Seven out of ten of these neurons were also excited by iontophoretic application of DA. The influence of alpha-methyldopamine was not reported. On the basis of these data connor suggested that the depression of striatal unit activity produced by stimulation of the $S N$ is mediated by a direct dopaminergic nigrostriatal pathway. However the excitatory effects of nigral stimulation remained unexplained.

Ohye et al (1970) studied the influence of nigral lesions on the spontaneous activity of the striatum. ohye reasoned that if the nigrostriatal pathay has a tonic inhibitory influence on neuronal activity in the cd, 
lesions of the $S N$ should release the inhibition and result in an increased firing frequency of striatal units. Following chronic electrolytic lesions of the $S N$ the average rate of neuronal discharge was greater on the ipsilateral as compared to the contralateral side. The results from one control animal indicated that the unit activity in the contralateral side remained unchanged.

Based on the these findings it became generally believed that $D A$ functioned as an inhibitory transmitter in the nigrostriatal pathway. In summary, 1) DA and its synthetic enzyme are present in the $c d$, and $D A$ is localized to terminals; 2) DA is released in the cd following stimulation of the $S N$; 3) nigral stimulation or iontophoretic application of DA results in a depression of spontaneous activity of the majority of striatal neurons and alpha-methyldopamine blocks both effects and finally 4) an electrolytic lesion of the $\mathrm{SN}$ apparently results in a release of a tonic inhibition of striatal units. However certain findings contrary to the hypothesis remained unexplained. McLennan and York (1967) reported excitation of striatal units following nigral stimulation. Although an adrenergic blocker blocked the effects of iontophoretic application of $\mathrm{DA}$, the excitation observed following nigral stimulation was not influenced. Connor also reported the nigral stimulation evoked single units with a constant latency. Alpha-methyldopamine was only occasionally effective in blocking the response. Prigyesi and Purpura (1967) observed excitation of single units 
with an average latency of $20 \mathrm{msec}$ following stimulation of the SN. The units followed well up to a frequency of 40 Hz. They were detected most often in the central regions of the striatum. Previous lesions of the cerebral cortex and other structures with efferents to the cd did not influence the probability of detectng evoked units. Feltz and Albe-Fessard (1972) detected 419 cells evoked by nigral stimulation. Again they were found most often in the medial two thirds of the nucleus, had a latency of 10 to $25 \mathrm{msec}$, and had a stable latency following stimulation applied at frequencies up to $50 \mathrm{~Hz}$. They also reported inhibition of 102 of a 166 spontaneously active neurons. Intracellular studies (Buchrald et al, 1973; Hull et al, 1970. 1974; Kitai et al, 1975, 1976) have shown that an EPSP or an EPSP-IPSP sequence is the predominant response recorded in striatal neurons following stimulation of the SN. Lesions of dopaminergic neurons by injection of 6-OHDA into the medial forebrain bunde do not influence the excitation or inhibition observed following nigral stimulation (Feltz and DeChamplain, 1972). Finally, Hull et al (1973) performed a series of elegant and well controlled experiments to re-examine the tonic influence of the nigrostriatal pathway on striatal neurons.

In the first experiment electrodes were positioned in the cd on both the left and right side. Single units were recorded simultaneously from both sides to control for changes in the state of arousal of the animal. In seven control animals the mean firing rate was not significantly 
different on the tyo sides. Following chronic lesions of the medial forebrain bundle or $\mathrm{SN}$ the mean firing rate for neurons in the ipsilateral ca was unchanged from that of control animals. However the mean for neurons in the contralateral cd was reduced by about $75 \%$. Although the rate of firing was unchanged in the ipsilateral ca the pattern of activity was altered from the usual bursting pattern to a more regular firing pattern with fewer short or long intervals. Following the acute experiments the dopamine content of each striatum was determined. A 75 to $90 \%$ reduction in $D A$ was found in the ipsilateral striatum as compared to the contralateral side or to control animals. Lesions of the tegmentum above the $S N$ also resulted in a decrease in the mean firing rate of spontaneous units in the contralateral cd with no change on the ipsilateral side. Howerer the DA levels in the ipsilateral ca were unchanged from controls.

In the second experiment three monkeys had chronically implanted lesioning electrodes placed in the region just dorsal to the $S N$ on one side, and a single unit recording device was implanted over both caudate nuclei. Before lesioning the animals, simultanecus control records of a number of striatal units were obtained over a period of several months. Electrolytic lesions were then placed in the ventral tegmentum on one side by asing the already implanted lesioning electrodes. After waiting two weeks for recovery, data from another sample of spontaneous units were obtained. The results were similar 
to the first experiment. Again there was no change in the mean firing rate on the ipsilateral side ccopared to control values and there was a significant increase in the mean firing rate on the intact side. There was no significant difference in DA content of the two caudate nuclei. These findings indicate that lesions of the nigrostriatal pathway do not release striatal neurons from a tonic inhibitory influence as suggested by ohye. In fact lesions in and near the pathway have a major effect on the contralateral striatum. Furthermore these changes are independent of the DA content of the Cd.

clearly, the hypothesis that nigral stimulation exerts an inhibitory influence on the striatum by releasing $D A$ as a synaptic transmitter must be reevaluated. Frigyesi and purpura (1967) postulated two distinct nigrostriatal pathways subserving the inhibitory and excitatory actions on striatal neurons. Feltz and Albe-Fessard (1972) suggested that there is a single excitatory input impinging on striatal target cells and that the inhibitory influence is the result of an intrinsic mechanism within the striatum. However, these suggestions have remained speculative in view of the lack of electrophysiological identification of various populations of neurons within the striatum responsive to nigral stimulation.

The present experiments were designed to characterize the synaptic influence of the nigrostriatal pathway. The 
extraceliular responce of neurons in the striatum were recorded in urethane anaesthetized rats. First, stimulation of the SN, GP, IC, or DRN vas used to determine the electrophysiological properties of striatal neurons and to identify subpopulations of neurons ithin the nucleus. Second, pharmacological agents were systemically or iontophoretically administered to determine their influence on striatal neurons already electrophysiologically identified. Third, chemical or electrolytic lesions were placed in the nigrostriatal and associated pathuas to examine the dependence of the electrophysiological properties on known neuronal systems. The results indicate that a) dopamine functions as an excitatory transmitter in the nigrostriatal pathway, b) that the inhibition observed in the striatum following nigral stimulation is the result of an inhibitory collateral system dependent on interneurons ithin the cd, (Richardson et al, 1977) and c) that a neuronal pathway exists between the dorsal raphe nucleus and the striatum. stimulation of this pathway produces a potent inhibition of striatal neurons (Miller et al, 1975). 


\section{METHODS}

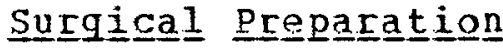

Acute recording experiments were performed on a total of 83 male Wistar rats weighing between 250 and 400 g. A11 surgical preparation and subsequent experimentation were performed under urethane anaesthesia. Urethane was given I. P. in a dose of $1.5 \mathrm{~g} / \mathrm{kg}$ and a satisfactory level of anaesthesia was maintained by supplemental I.P. injections during the experiment. Body temperature was monitored by a rectal thermistor probe and maintained between 36 and 37 degrees centigrade by a thermostatical1y controlled heating pad.

The animals were placed in a Kopf stereotaxic frame with the incisor bar at 4.0 to $5.0 \mathrm{~mm}$ below zero thereby positioning the skull in a horizontal plane. A rectangular region of calvarium was removed to expose an area of cortex roughly corresponding to boundaries $2.5 \mathrm{~mm}$ anterior and $4 \mathrm{~mm}$ posterior to bregma and $4 \mathrm{~mm}$ on either side of the saggital suture. The exposed cortex was covered with warm saline throughout the experiment. 


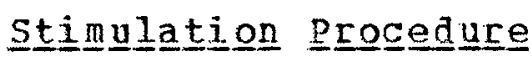

Concentric bipolar metal electrodes were used, for electrical stimulation. These had tip separations of 0.3 to $0.5 \mathrm{~mm}$ and a DC resistance of 75 to $100 \mathrm{k}$ ohms in normal saline. Using coordinates from the atlas of Konig and Klippel (1963) the electrodes were positioned in one or more of the following regions: $5 N$, GP, IC, intralaminar and parafascicular nuclei of the thalamus, IPT or nigrostriatal bundle.

Single square wave pulses of $0.1 \mathrm{msec}$ duration and 5 to 20 volts (v) intensity were delivered through a Grass isolation unit. An ortec crystal clock controlled the rate and timing of stimulation.

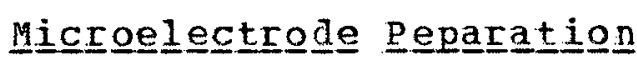

Extracellular unit activity was recorded using either single micropipettes prepared from corning capillary tubing, or multipipette assemblies prepared from custom made 7 barrel electrode blanks. The pipettes were heated and drawn to fine tips in a vertical microelectrode puller. The tips were then broken under microscopic observation to diameters of 1-2 qm for single pipettes and 4-8 um for multipipettes.

The single pipettes and central recording barrel of pipette assemblies were filled with either $4 \mathrm{M} \mathrm{NaCl}$ or Pontamine sky blue in $4 \mathrm{M}$ sodium acetate. The remaining 
barrels of the pipette assemblies were filled with the following solutions: sodium 1-glutamate $11 \mathrm{M}, \mathrm{pH} 4.0$, Regis Chemical), dopamine hydrochloride $(1 M, p H 4.0$, Regis Chemical) and alpha-flupenthixol $(0.5 \mathrm{M}, \mathrm{pH} 4.0, \mathrm{H}$. Lunbeck and Co-). The drugs yere ejected iontophoretically using appropriate anionic and cationic currents. Haloperidol $(0.5$ to $2.5 \mathrm{mg} / \mathrm{kg}$. McNeil Laboratories) and alpha-flupenthixol $(0.5$ to $2.5 \mathrm{mg} / \mathrm{kg})$ were also given intravenous1y.

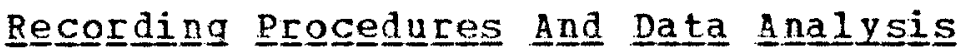

Micropipettes were positioned according to stereotaxic coordinates from the atlas of Konig and Klippel (1963). An AB Transvertex Microstep unit was used to lower the electrode in steps of $14 \mathrm{~m}$.

A11 recorded potentials were first passed through a custom made voltage follower for impedence matching. The signals were then led through a bandpass filter $(1$ to $10 \mathrm{~K}$ Hz), amplified by a Tektronix $3 A 9$ differential anplifer and displayed on a Tektronix 564 storage oscilloscope or a RM 565 dual beam oscilloscope. A polaroid camera was used to photograph the sweeps.

The amplified signal was also passed through a voltage discriminator. The discriminator produced an output pulse if an action potential occurred ith an amplitude above a manually set threshold. The pulses were integrated and displayed on a paper chart to give a 
continuous record of firing frequency. The pulses also fired a schmiat trigger of a pDe-8l computer for real time generation and display of post stimulus time histograms (RST). Permanent records were obtained from an analogue $x$ Y plotter.

The PST was used to assess a change in neuronal Eiring following stimulation of a particular brain region. The $x$, or latency axis, of the histogram was divided into a predetermined number of equal time periods referred to as bins. The latency of each discharge was measured relative to a timing pulse from the crystal clock, and the appropriate bin was incremented. Data were collected during 25 to 100 cycles of the clock. The relative probability of discharge at a particular latency was represented on the $Y$ axis by the height of the histogram bar for that bin. The clock also initiated a stimulus presentation at a constant latency from the timing pulse. Therefor the profile of the histogram represented the influence of the stimulus on neuronal discharge. A peak indicated an increased, and a trough a decreased probability of discharge, whereas a flat profile indicated a lack of influence by the stimulus fGerstein and Kiany. $1960)$ 


\section{보노으으므}

Sites of stimulation were marked by passing 10 to 15 ma of DC anodal current for 10 seconds through the center core of the stimulating electrode. Perfusion of the brain with potassium ferrocyanide allowed subsequent identification of a Prussian blue spot in histological sections. Recording sites were marked by leaving the tip in place during fixation so that the electrode tract could be visualized histologically. In some preparations the recording electrode contained pontamine sky blue for precise identification of the recording site. After dye was ejected electrophoretically a blue spot could be located on sections.

Following each experiment the animal was perfused intracardially with $200 \mathrm{ml}$ of $0.9 \%$ sodium chloride followed by $100 \mathrm{ml}$ of a mixture of potassium ferrocyanide and $10 \%$ buffered formalin. Frozen sections were then cut at intervals of $50 \mathrm{qm}$. These sections vere mounted on glass slides, dehydrated and stained with cresyl violet or saffranin. Electrode sites could then be located under a microscope.

Retrograde transport of horseradish peroxidase (HAP, type 4 sigma Chemicals) was examined in 11 preparations. The animals were anaesthetized ith pentobarbital 150 $\mathrm{mg} / \mathrm{kg}$. I.P.). In 6 animals 0.1 ul of a $10 \%$ solution of HRP in saline vas injected unilaterally into the SN by a stereotaxically guided microsyringe. Similar injections 
were made unilaterally or bilaterally into the cd of 5 animals. Following a survival period of 24 hours the rats were killed and perfused at room temperature with a solution of $3 \%$ paraformaldehyde and $2 \%$ glutaraldehyde in 0.05 phosphate huffer (pH 7.5.). The brains were removed and allowed to stand for 24 hours in phosphate buffer containing $5 \%$ sucrose. Frozen sections were then cut at 50 um intervals, treated to reveal peroxidase activity according to the method of Graham and Karnovsky (1966) and examined microscopically under dark field illumination.

\section{Lesionining And Ass}

Lesions interrupting afferent pathways to the striatum were carried out in preliminary operations 3 weeks to 2 months prior to acute electrophysiological experiments. Electrolytic lesions were performed under pentobarbital anaesthesia $(50 \mathrm{mg} / \mathrm{kg}, \mathrm{I} . \mathrm{P}$.$) by passing up$ to 2 ma of DC curcent for 15 to 30 seconds through stereotaxically placed metal electrodes. Iesions were made in the intralaminar and parafascicular nuclei of the thalamus of 3 animals, in the $s N$ of 5 animals, and in the ventral tegmentum at the level of the $S N$ of 3 animals. In another 4 animals aspiration of the cerebral cortex dorsal and rostral to the striatum was carried out.

In six animals selective depletion of striatal DA was achieved by using 6-hydroxydopamine hydrobromide (6-OHDA, Regis Chemical). Animals were pretreated with 
desmethylimipramine $(25 \mathrm{mg} / \mathrm{kg}$ I.P. $) \quad 1$ hour prior to unilateral injection of 6-OHDA 12 ug dissolved in 4 ul of $0.15 \mathrm{M}$ NaCl containing $1 \mathrm{mg} / \mathrm{ml}$ of ascorbic acid) into the nigrostriatal bundle at the level of the hypothalamus. The effectiveness of the chemical lesions was confirmed by measuring the dopamine content of the ipsilateral striatum compared with the contralateral control according to the method of McGeer and McGeer (1962).

Orthograde axonal transport of tritiated leucine from the dorsal raphe nucleus to the striatum was examined in 5 rats. Unilateral electrolytic lesions 12 ma for 30 seconds) were first made in the medial forebrain bundle at the level of the hypothalamus. Twenty four hours later 0.6 $\mathrm{ul}$ of a solution containing $5.76 \mathrm{Ci} / \mathrm{mmole}$ of tritiated lencine (specific activity $50.0 \mathrm{ci} / \mathrm{mmole}$ ) was injected by microsyringe into the dorsal raphe nucleus. Animals were sacrificed 24 hours later and the brains were removed and aissected rapidly into samples from both $c d$ and overlying cortices. Fach sample was weighed and the content of tritiated protein determined by the method of Fibiger et a1 (1972). 


\section{BESULTS}

\section{Bursst Respponse}

A burst of excitation was the most frequent response recorded in the cd following electical stimulation of the ipsilateral SN. The burst response was usually in the form of 2 to 8 "ripples" of the recording baseline with superimposed low amplitude spikes (50 to $300 \mathrm{uv}$ ), although occassionally spikes were not present. The frequency of spikes within the burst was from 200 to $900 \mathrm{~Hz}$. The response began at a latency of 3 to $10 \mathrm{msec}$ and had a duration of 3 to $7 \mathrm{msec}$. In figure 1,4 ripples with superimposed spikes are seen in the response to nigral stimulation at intensity of 20 volts.

Threshold stimulation evoked a response consisting of a few low amplitude spikes. As the stimulus intensity was increased the amplitude of the individual components of the burst became larger, and ripples or spikes occurred with longer, as well as shorter, latencies. At low frequencies of stimulation $(1 \mathrm{~Hz})$ the burst resfonse had a very consistent latency and configuration. However, with increased rates of $S N$ stimulation (above $10 \mathrm{~Hz}$ ) the amplitude of the bursts decreased and the configuration became variable. They failed to occur at stimulus frequencies above $40 \mathrm{~Hz}$ (figure 1 and 2).

The response occurred througbout all regions of the Cd explored. Several regions responding with a burst of 
EIGURE 1. An example of the influence of stimulus intensity of nigral stimulation on the burst response recorded in the $\mathrm{cd}(7,10,15,20$ volts). Note that a stimulus intensity of $7 \mathrm{v}$ evokes a single spike. This response becomes incorporated into the burst as the stimulus intensity is increased.

Note: these and each subsequent photograph show 5 superimposed oscilloscope sweeps unless otheryise stated. The arrow refers to the stimulus artifact. 

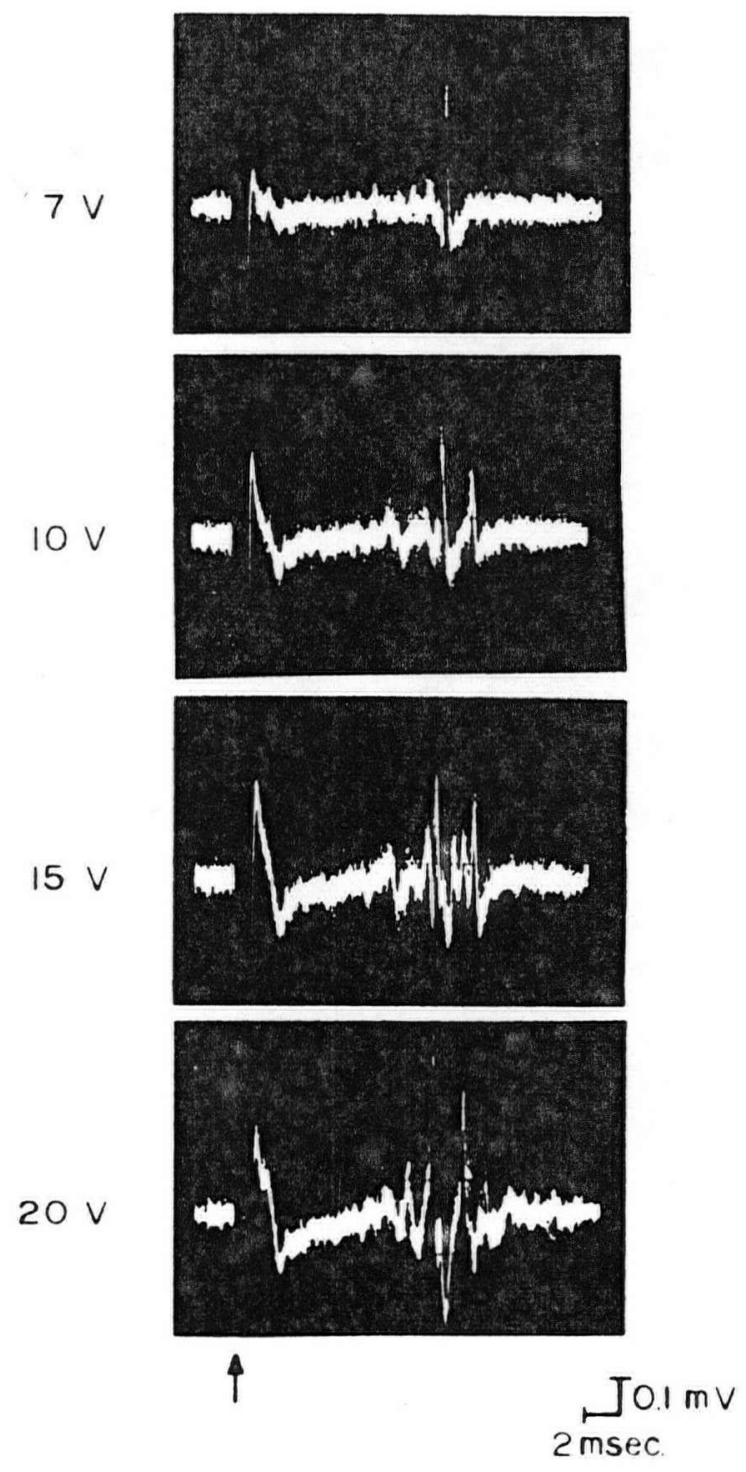
FIGURE 2. Characteristics of the burst response at different frequencies of nigral stimulation (1, $20.40 \mathrm{~Hz}$. The response failed at a frequency of $40 \mathrm{~Hz}$. 


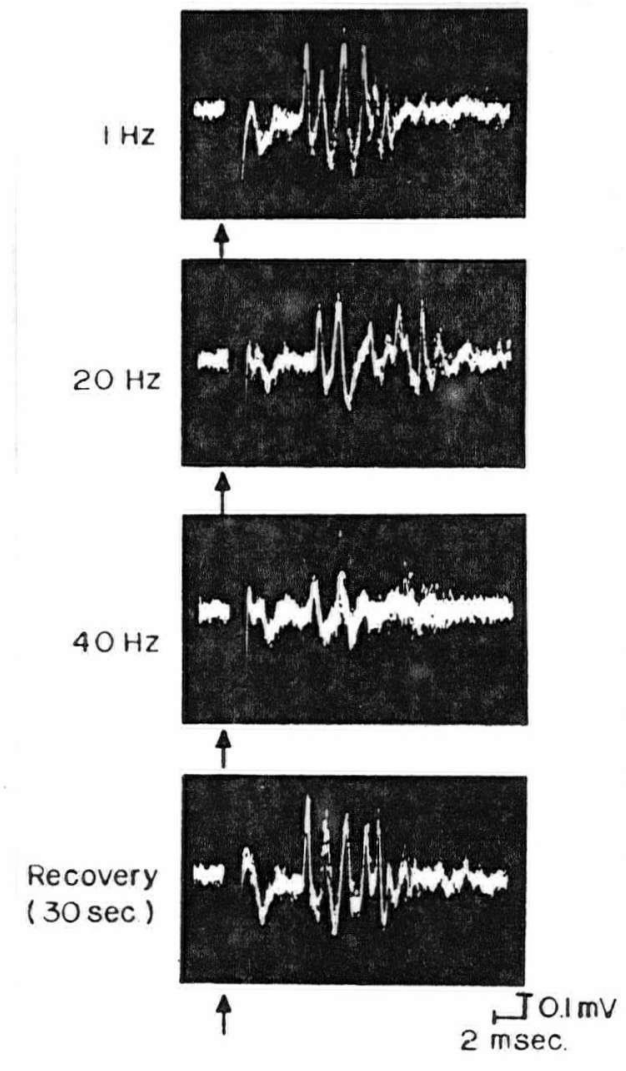


excitation would be encountered on one electrode tract, each with a different latency and duration. Within a region responding to nigral stimulation the response was continuously present during large vertical movements of the electrode (Eigure 3). Each active region spanned about 200 to $300 \mathrm{um}$ separated by a 200 to $400 \mathrm{um}$ region of "silence". Small movements of the electrode within an active region resulted in qualitative changes in the recorded response (figure 4). Relative amplitude of spikes in the response would change during the movement and spikes sometimes appeared or disappeared. When the position of an electrode recording a burst was marked with Pontamine sky blue, it was always located within the neuronal tissue between the fascicles of cortico-spinal fihers traversing the striatum. Conversly the burst responses were not recorded when the electrode tip was located within regions of bigh fiber density.

Bursts of excitation could be recorded in the ca only when the stimulation site was accurately located vithin the SN. Placement of the stimulating electrode dorsal or caudal to the $\mathrm{SN}$ abolished the response (figure 5).

Similar burst responses were recorded in the cd following stimulation of the GE. IC, or IPT. Although the responses were of a slightly shorter latency their characteristics were identical to those seen follouing $S N$ stimulation. often a recording location in the cd was responsive to more than one stimulation site. For example 
FI GOPE 3 - Variability in the burst response evoked by nigral stimulation. The electrode was moved along a vertical tract. in the striatum extending from 4.50 to $4.82 \mathrm{~mm}$ below the surface of the cortex. The photograph on the right is of a coronal section through the striatum. The arrows point to Pontamine sky blue marks left by the recording electrode. The left spot is in the midale of a region responding with a burst. The two spots on the right mark the begining and end of a region of the electrode tract continuously responsive to nigral stimulation. 
A.
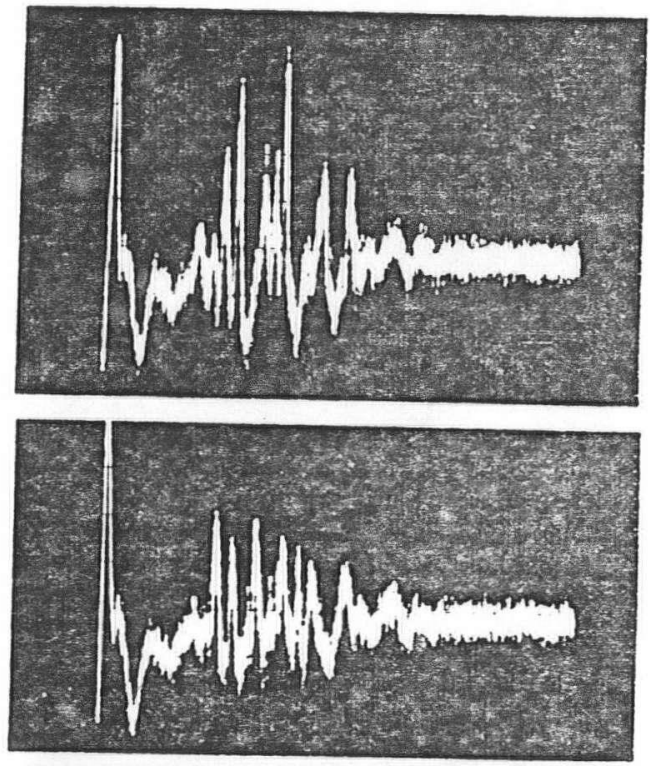

$=4.59$

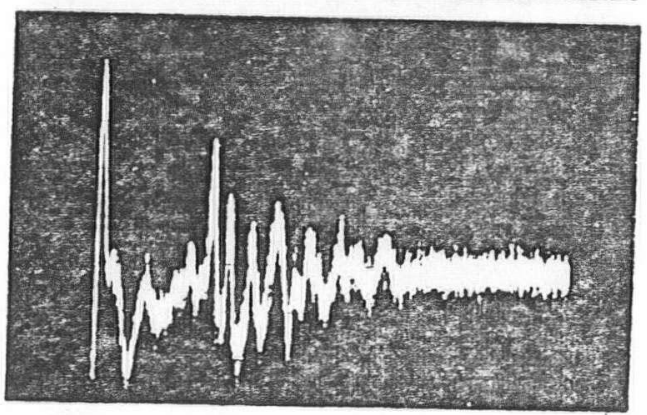

$\uparrow$
$B$.

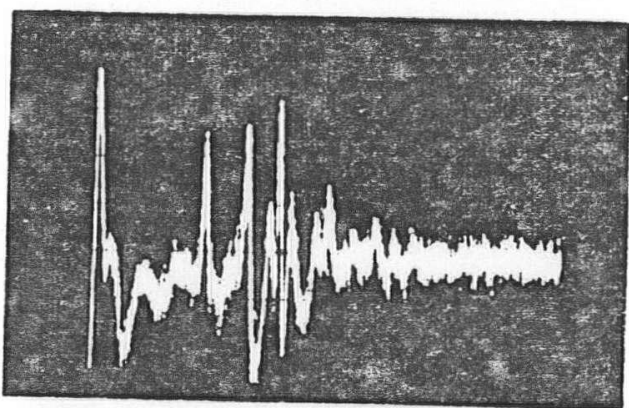

$V=4.69$

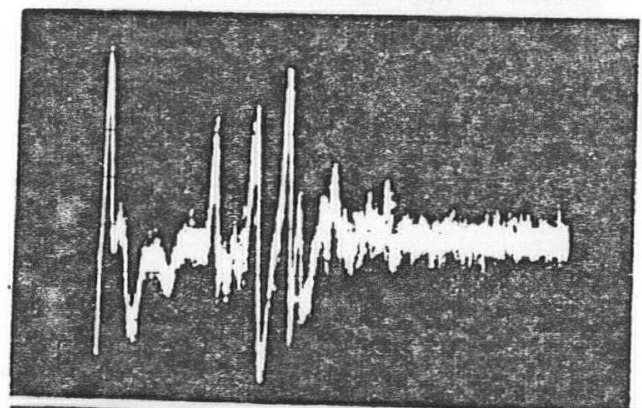

$V=4.82$

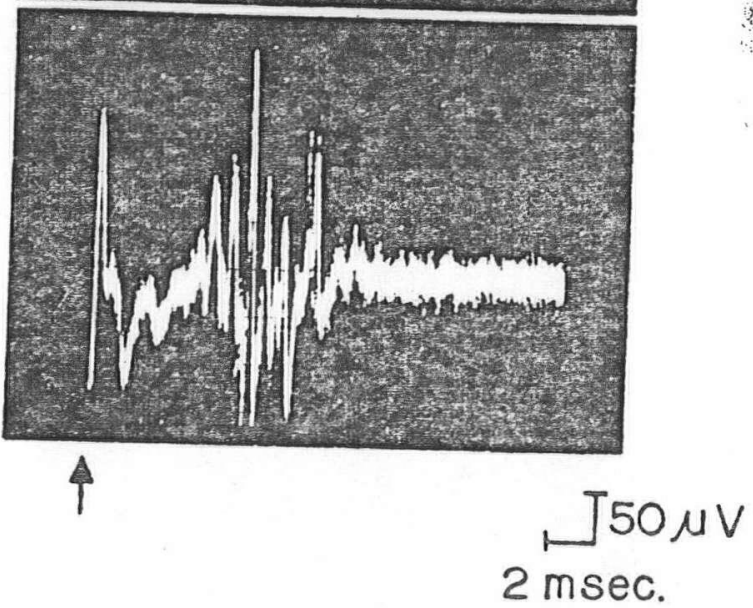


FIGURE 4 - Changes in the burst response recorded in the striatum following nigral stimulation as a result of small changes in the position of the recording electrode $(4.00,4.04,4.06 \mathrm{~mm})$. Note the change in sharpness and amplitude of the peaks. 

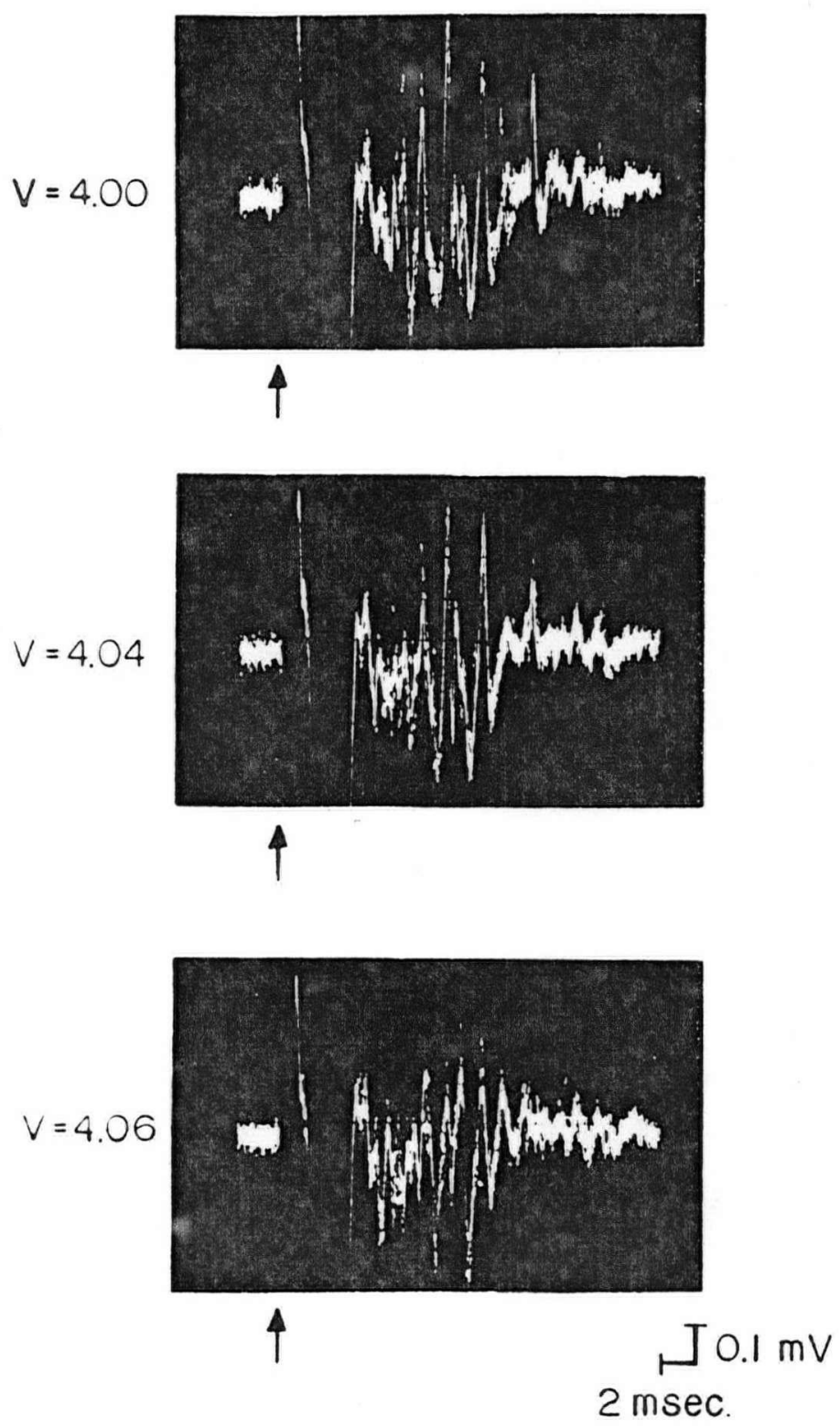
FIGURE 5 : A burst response is recorded in the cd only if the stimulating electrode is accurately placed in the $S N$ (top). Stimulation at a site posterior or dorsal to the $\mathrm{SN}$ fails to evoke a response (bottom). 

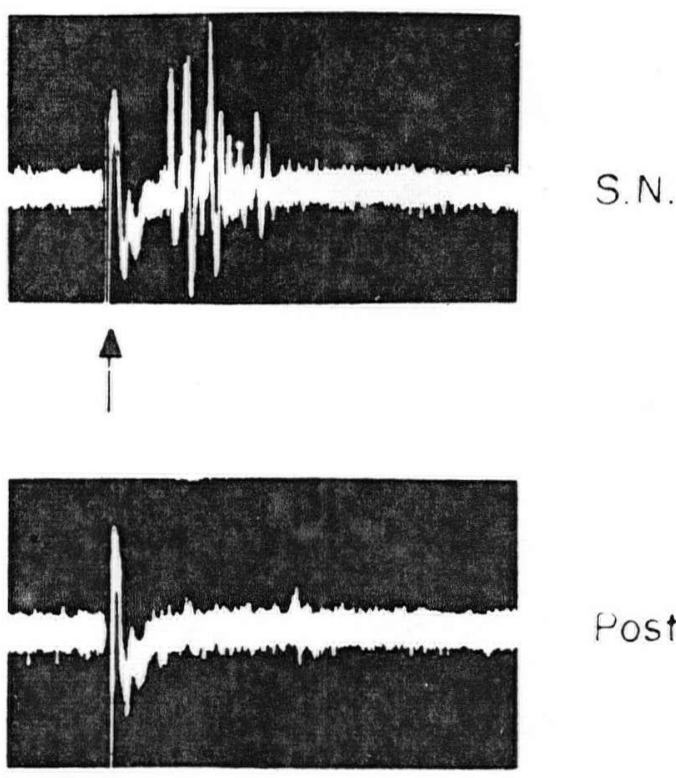

Posterior to S.N.

4

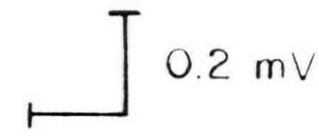

$10 \mathrm{msec}$ 
either $S N$ or thalamic stimulation was followed by a burst response in certain regions of the cd. Most striking, however, was close correlation between regions responding to stimulation of the IC and SN. Once the IC electrode was positioned to produce a burst in a region responsive to $\mathrm{SN}$ stimulation, all other regions of the cd explored responded in a similar fashion to stimulation of either site (figure 6).

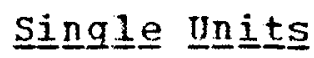

Single unit activity has been recorded from more than 300 neurons in the cd. Some were spontaneously active with a mean frequency of $5.2 \mathrm{spikes/sec}$ and a range of 1 to 20 spikes/sec. However the majority only fired when glutamate was ejected iontophoretically from one barrel of an electrode assembly. Spontaneous or glutamate induced activity of $65 \%$ of these was depressed by iontophoretically applied DA (figure 7). The remaining cells were non-responsive or, in a minority of cases, responded with an increased firing rate. The single units could be differentiated into two groups based on spike amplitude and their response to stimulation of the SN.

The majority of units had low amplitudes ranging from 150-300 wV. They were detected with equal probability in al1 regions of the cd explored. A spontaneous unit and a burst response following $S N$ stimulation were often recorded simultaneously from the same electrode site. The 
EIGURE 6. Effect of an electrolytic lesion of the IC on the burst response evoked by nigral stimulation. Note the similarity of the response to stimulation of the $\mathrm{SN}$ (top left), IC (middle), and GP (bottom). A11 responses were recorded from the same animal without adjusting the position of the recording electrode. An acute lesion was performed by passing current through the already positioned capsular electrode. Following the lesicn, nigral stimulation (top right) no longer evoked a response. 

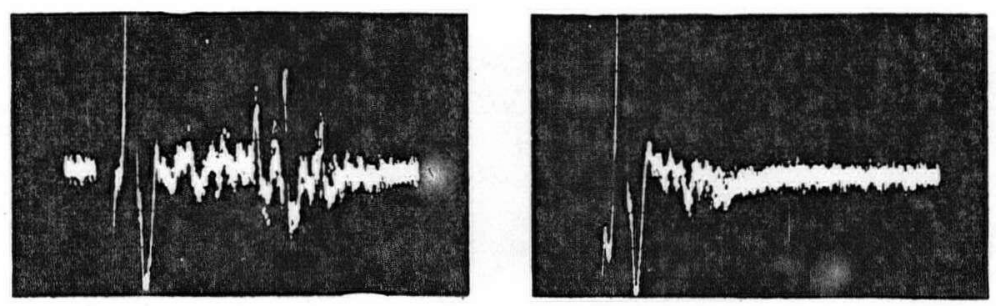

† SN (Control)

T SN (IC Lesion)
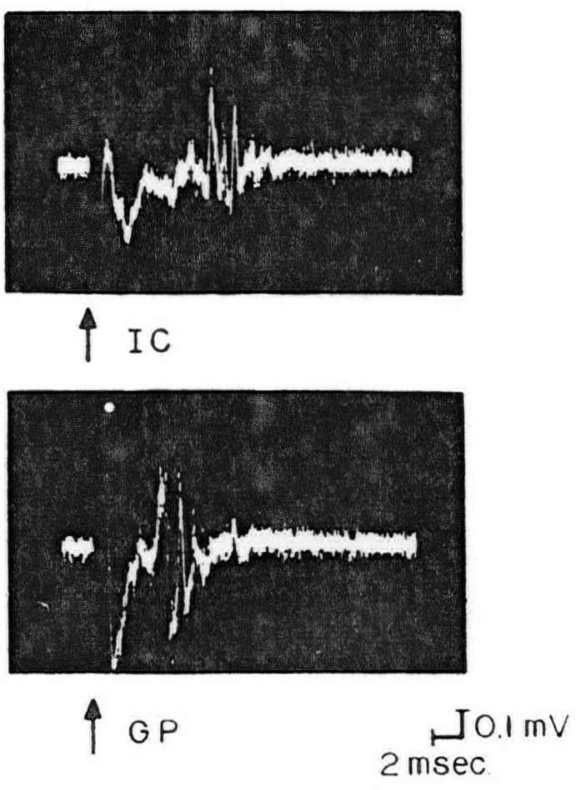
A) the response of spontaneously discharging striatal neurons to single pulse stimulation of the SN. The photographs show spontaneous units responding with a period of inhibition. In both examples a burst occurred within the first $10 \mathrm{msec}$ of the response (masked by the stimulus artifact). The PST below each photograph shows the summation of the responses to 50 stimuli.

B) rate records of the same neurons indicating the inhibitory action of iontophoreticaly applied DA (DA 60 and $50 \mathrm{nA}$ ). The periods of application are shown by the solid horizontal bars. Note: these and each subsequent PST show the summation of 50 responses. The stimulus artifacts are indicated by the first large deflection of the histogram. The binwidth is $10 \mathrm{msec}$ in each case. 

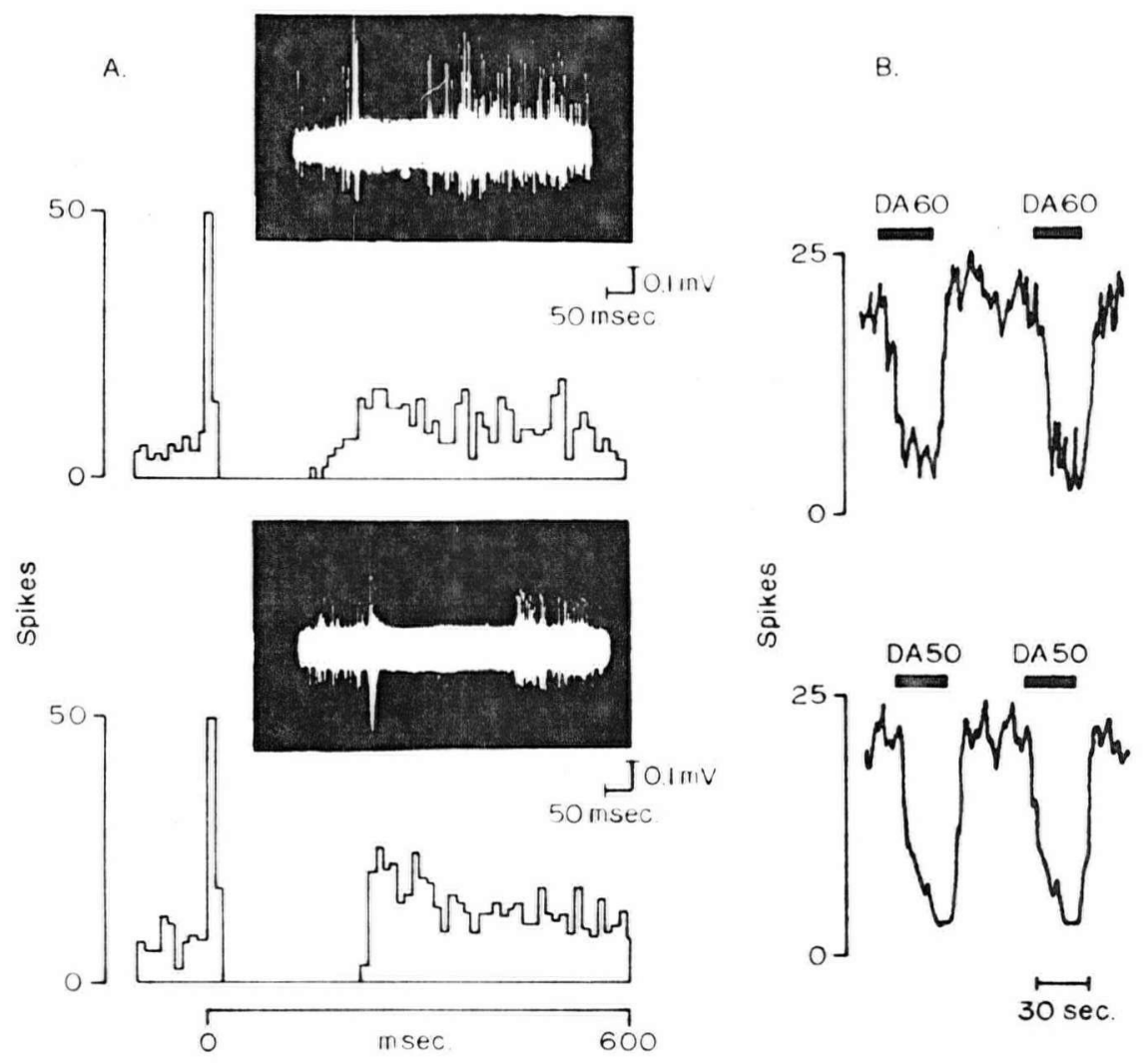
spontaneous unit, in some cases, had an amplitude similar to one of the spikes within the burst. If the vertical position of the recording electrode was moved the spontaneous unit and the spike within the burst underwent the same alteration in amplitude. Following a burst response the spontaneous activity was completely inhibited for 60 to $300 \mathrm{msec}$ (mean $175 \mathrm{msec}$ ) (figure 8). A slight rebound of excitation lasting 50 to $150 \mathrm{msec}$ frequently followed the period of inhibition. The minimum stimulation intensity required to produce inhibition of spontaneous activity was, in most cases, equal to or greater than the intensity required to produce a burst response.

Small amounts of glutamate ejected iontophoretically often prolonged and intensified the burst response. Hovever, higher ejection currents of glutamate caused a decomposition of the response and a coincidental loss of the inhibitory effect normally observed following nigral stimulation (figure 9). Low amplitude units resfonded in a similar manner following stimulation of the IPT or GP. The unit often appeared within the burst response and its spontaneous activity was inhibited for up to $300 \mathrm{msec}$.

The second group of single units had action potentials with amplitudes greater than 300 uv. spontaneous or glutamate induced large amplitude units were also encountered most often in regions responding with a burst of excitation following nigral stimulation and were always strongly inhibited for 60 to $300 \mathrm{msec}$ 
FIGUIE 8. The top photograph is of a burst response recorded in the cd following nigral stimulation. The PST shows the inhibitory influence of nigral stimulation on the spontaneous activity of a neuron in the same region. 
Spikes

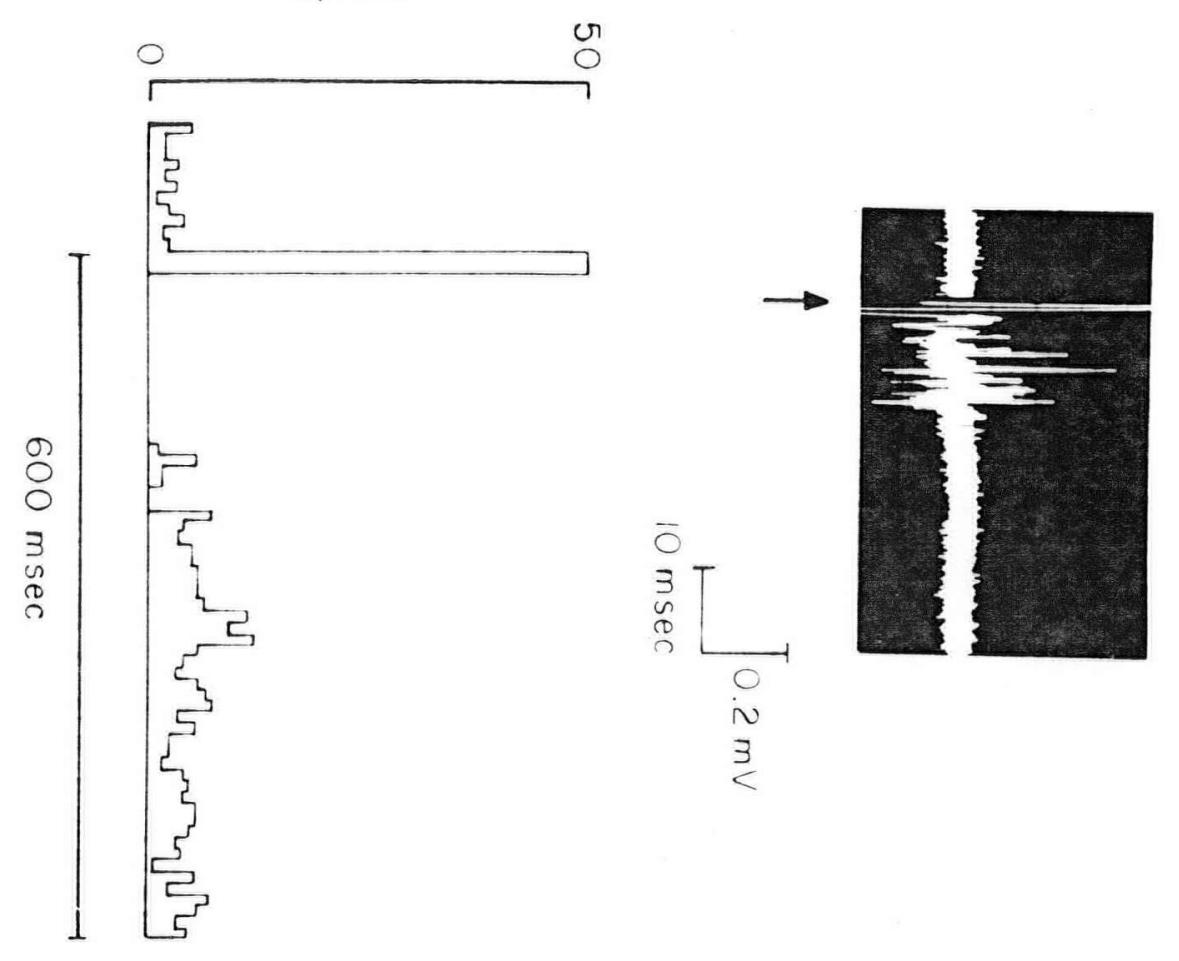

$\underset{A}{\mathrm{~B}}$ 
FIGUBE 2- The influence of glutamate on the response evoked in the striatum by nigral stimulation.

n) the burst response has been prolonged by application of $10 \mathrm{nA}$ of glutamate. The PST shows inhibition of a spontaneous neuron following each stimulus.

B) glutamate applied at $75 \mathrm{nA}$ attenuated the burst response. There was a coincidental loss of inhibition of the spontaneous neuron as demonstrated by the PST. 

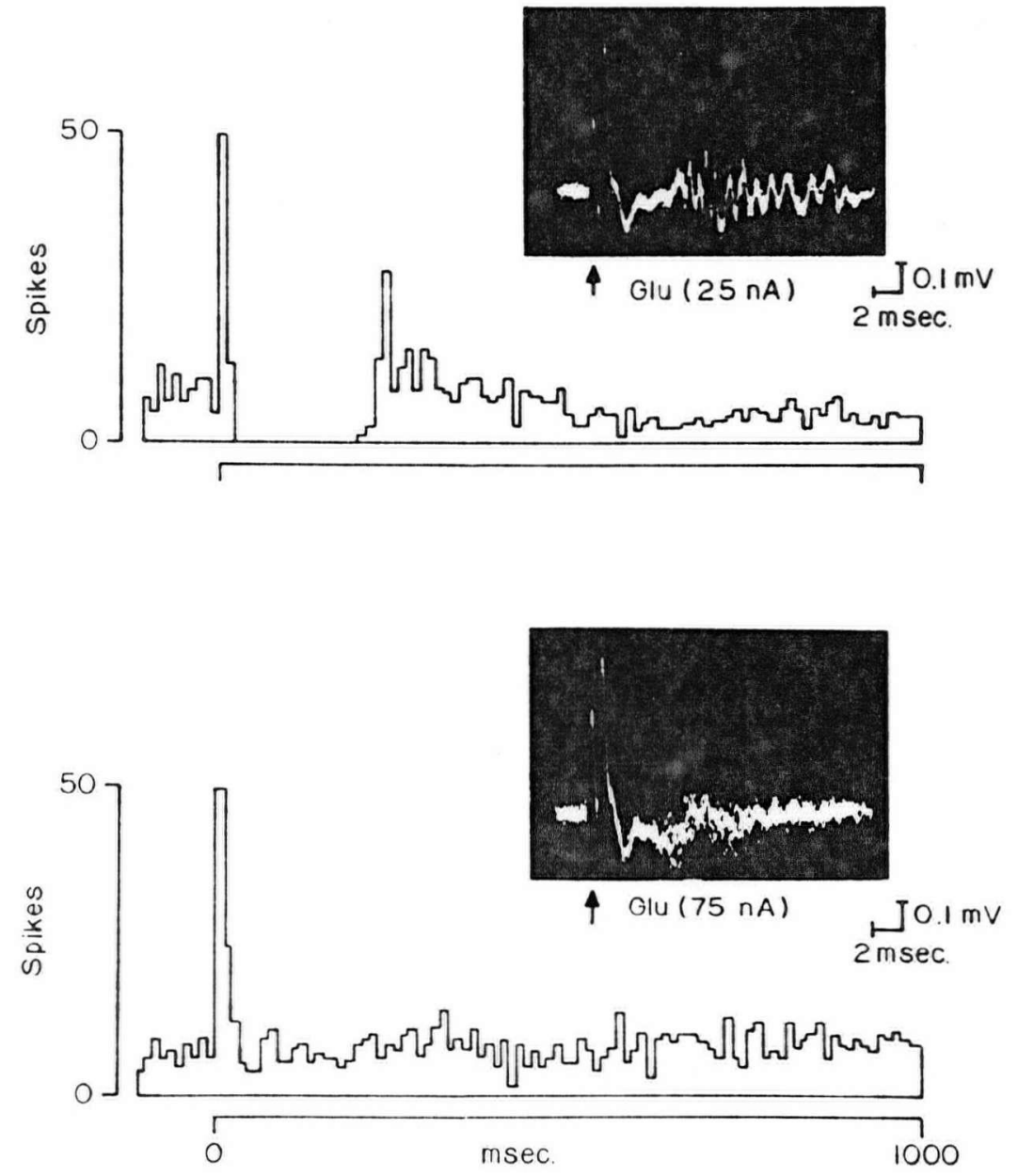
following the burst response. However, unlike low amplitude units, they were more likely to be detected in the central core of the cd and were only rarely detected in the lateral region of the nucleus. These units often responded with single action potential during the burst. The high ampitude of the unit discharge made them clearly distinguishable from the low amplitude burst response (figure 10). The latency of an evoked discharge was in the range of 4 to 18 msec (mean $10.8 \mathrm{msec}$ ). At a stimulus frequency of $1-5 \mathrm{~Hz}$ the latency was constant although at higher frequencies there was considerable variablility. Units were unable to follow at stimulus frequencies above $50 \mathrm{~Hz}$.

High amplitude units could often be evoked with stimulus intensities below threshold for the burst response. If the stimulus intensity was then increased the burst appeared and the unit discharge would occur during the time course of the burst. However if the stimulus was increased to an intensity sufficient to evoke a maximal burst response the high amplitude unit often failed to discharge (figure 10)

In some instances a spontaneous or glutamate induced high amplitude unit was encountered in a region that did not respond with a burst following nigral stimulation. These units were never activated by nigral stimulation although their spontaneous activity was inhibited. Thalamic or GP stimulation also inhibited the high 
FIGURE 10. Activation of a large amplitude neuron in the striatum following stimulation of the $5 \mathrm{~N}$.
A) effects of increasing the stimulus intensity from 5 to 20 volts. Note that the large amplitude spike is blocked during the burst response at the highest intensity of nigral stimulation. Activation of the large spike following nigral stimulation at 1 and $10 \mathrm{~Hz}$. The response failed to follow at stimulus frequencies above $50 \mathrm{~Hz}$.
C) the same cell evoked antidromically by pallidal stimulation. The neuron could follow a stimulus frequency of $100 \mathrm{~Hz}$. 
A.
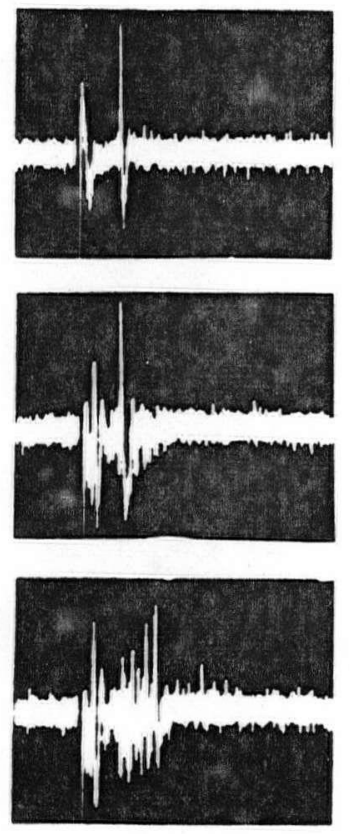

$20 \mathrm{~V}$
B.
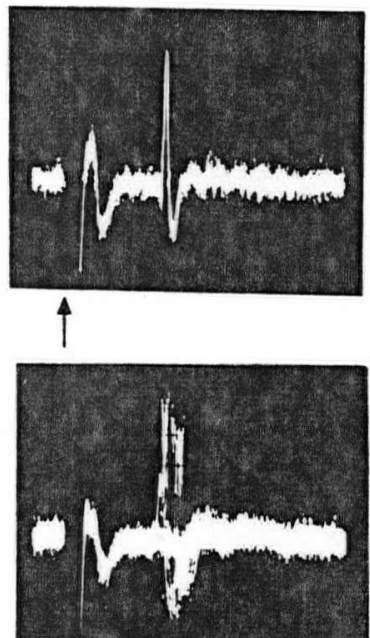

SN

$10 \mathrm{~Hz}$

$$
\underset{2 \mathrm{msea}}{\mathrm{J}} 50 \mu \mathrm{V}
$$

C.

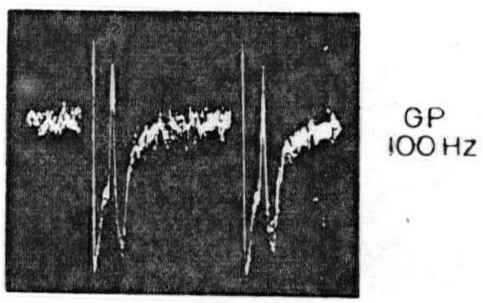

$$
\uparrow \quad \uparrow \underset{i m s e c}{\operatorname{Jin} 50 \mu \mathrm{V}}
$$

$\stackrel{\mathrm{J}}{\mathrm{J}} 50 \mu \mathrm{v}$ 
amplitude units for up to $300 \mathrm{msec}$ but did not evoke a unit discharge.

Stimulation of the tegmentum dorsal to the $S N$ caused a potent inhibition of both high and low amplitude unit discharge in the ca. However an initial evoked discharge or burst of excitation was never observed. Since ascending fibers from the raphe nuclei are known to course through this region the effect of raphe stimulation was determined. In 15 rats stimulating electrodes were positioned in the dorsal raphe nucleus (DRN). Stimulation of this region never produced excitation in the cd. However raphe stimulation did result in a potent inhibition of 33 of 45 glutamate induced or spontaneously active cd units (figure 11). The inhibition lasted 50 $380 \mathrm{msec}$ and was often followed by a 50 - 100 msec period of rebound excitation. Stimulation of the median raphe or at sites dorsal or ventral to the $D R N$ did not influence $C d$ units. 
FIGURE 11. Influence of raphe stimulation on spontaneous activity of striatal cells.

A) this cell was inhibited for $160 \mathrm{msec}$. Note that no early activation occurred.

B) the absence of inhibition following raphe stimulation in an animal with an electrolytic lesion of the ventral tegmentum. The lesion was performed 4 weeks previous to the acute experiment. 


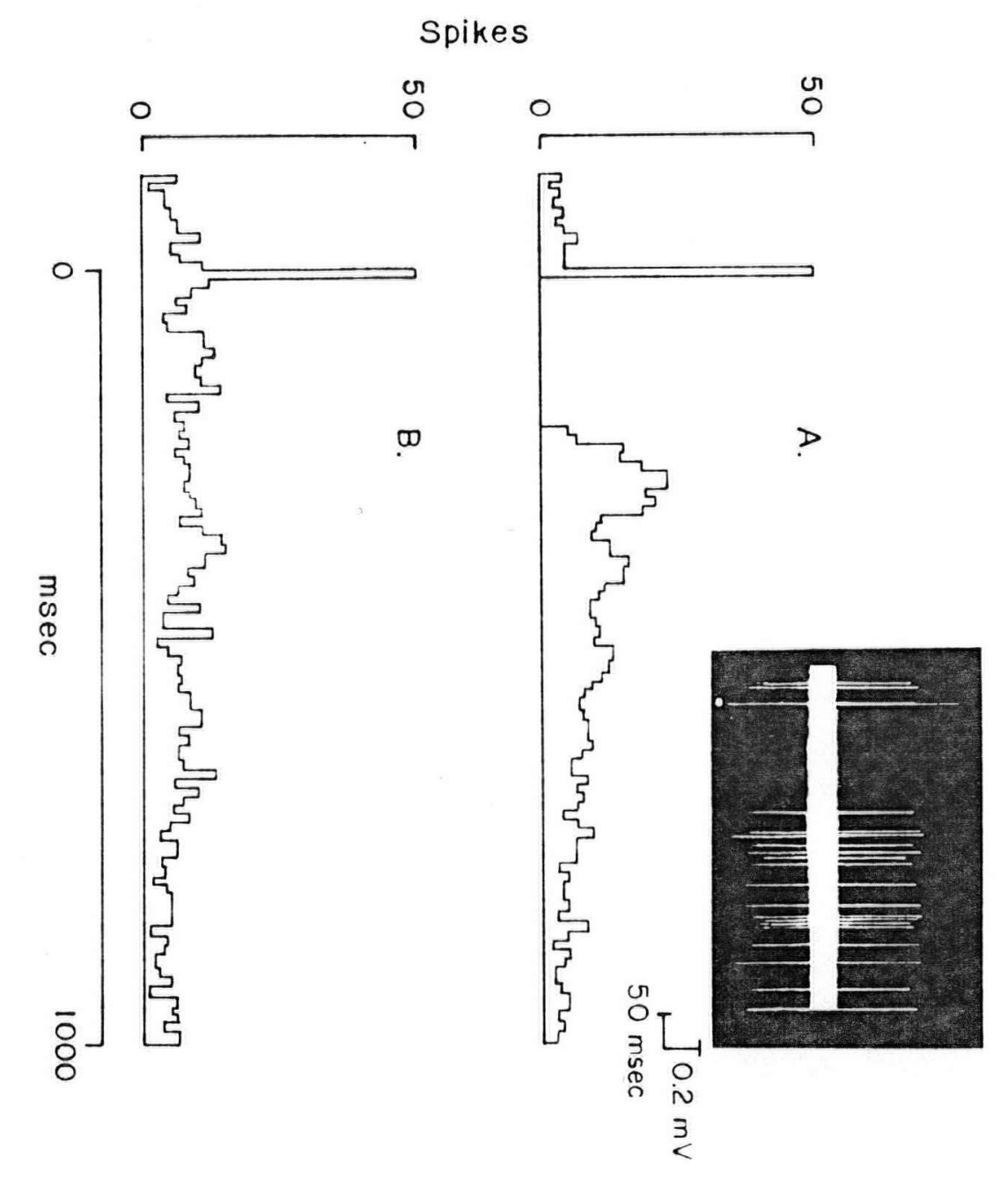

๒บ 


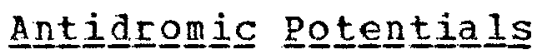

Antidromic activation of striatal units by nigral stimulation was only rarely encountered (12 cells) during the course of these experiments. A response was considered antidromic if it had a relatively short latency of firing (1.9 -4.5 msec), a constant latency with threshold stimuli and the ability to follog a stimulus frequency of $100 \mathrm{~Hz}$. In several neurons responding with these characteristics, IS-SD breaks in the action potentials were observed and stimulation at frequencies of 150 to $200 \mathrm{~Hz}$ resulted in failure of the so component. None of these antidromically activated units were spontaneously active. Histological verification of the recording placements indicated that neurons evoked antidromically following nigral stimulation were restricted to the ventral aspect and peripheral shell of the cd (figure 12).

Stimuli applied to the GP vere also observed to evoke large amplitude antidromic spikes in the cd with latencies of 1.1 to $2.6 \mathrm{msec}$. The responses occurred with a constant latency following threshold stimuli and they vere able to follow frequencies of 100 to $200 \mathrm{~Hz}$ (figure 10). Of 52 cells with these characteristics 27 were also orthodromically activated by nigral stimulation. These cells were the high amplitude units described in the section entitled "single units". Their refractory period was estimated as 1.0 to 2.0 msec since double pulse stimulation with an interstimulus interval of less than 


\section{FIGUEE 12 .}

A) diagramatic representation of the distribution of striatal cells labelled ith HRP. Each dot marks the position of one cell. Hatched area indicates the region where large amplitude neurons were synaptically excited by nigral stimulation. $A C$, anterior comissure; $C C$, corpus callosum; $S$, septum.

B) antidromic spikes evoked by nigral stimulation at a frequency of $100 \mathrm{~Hz}$. These resfonses were recorded from positions in the ventral and "peripheral shel1" of the nucleus corresponding to the dotted region shown in (A). Large deflection is the stimulus artifact.

C) photomicrograph of neurons labelled with HRP in the striatum corresponding to area outlined in (A) .

D) the injection site in the SN. 

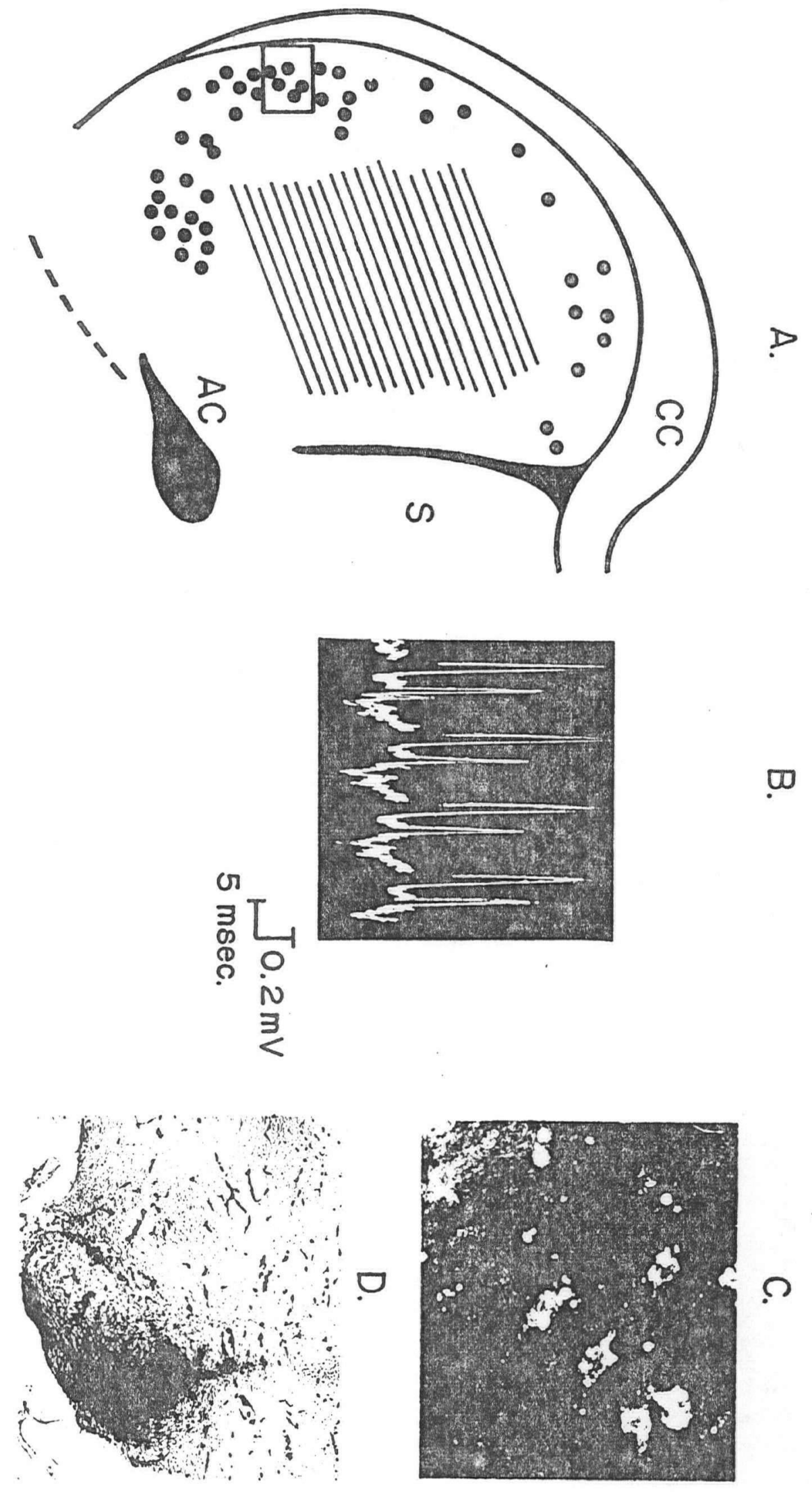
this period failed to illicit a double response. If the nigral orthodromic activation preceeded GP stimulation by less than $5 \mathrm{msec}$ the $\mathrm{GP}$ response was blocked. Collision extinction with a critical latent period of $5 \mathrm{msec}$ is reasonable for the neurons since it is approximately equal to the conduction time for the antidromic response (1.1 to $2.6 \mathrm{msec})$ plus the refractory period $(1.0$ to 2.0 msec). Histological verification of the location of 15 neurons responsive to stimulation of either the GP or $S N$ indicated that they were restricted to the centro-medial "core" of the striatum.

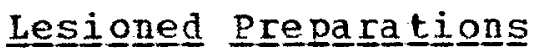

Large electrolytic lesions were placed in the Ipt of 3 animals and the DRN of another 3. In 4 animals the cerebral cortex was aspirated from the dorsal and rostral aspects of the cd. Three weeks to two months later acute electrophysiological experiments were performed. These lesions aid not influence the properties of the burst response, the high or low amplitude evoked unit discharge, or the potent inhibition of spontaneous activity observed in the ca following stinulation of the $S N$ (figure 13).

However similar electrolytic lesions of the IC in 5 animals completely blocked the effects of nigral stimulation. In two experiments, after the $5 N$ and IC electrodes were carefully positioned to produce a similar response at the same recording site in the $c d$, a discrete 
EIGURE 13. Persistence of the burst response following lesions of the IPT (left) or suction of the cerebral cortex overlying the cd (right). In both examples the response was recorded in the $\mathrm{Cd}$ following stimulation of the ipsilateral SN. The lesions were performed one month prior to the acute experiments. The PST demonstrates the persistence of the inhibitory influence of nigral stimulation on single unit activity after lesioning the IPT. A similar inhibition was observed in animals with previous ablaticn of the cortex. 


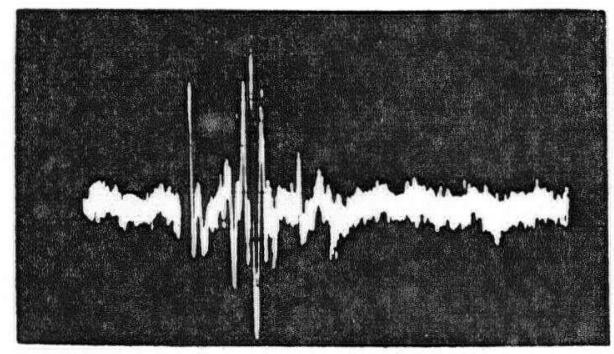

$\mathcal{L}_{\text {Thalamic Lesion }}$

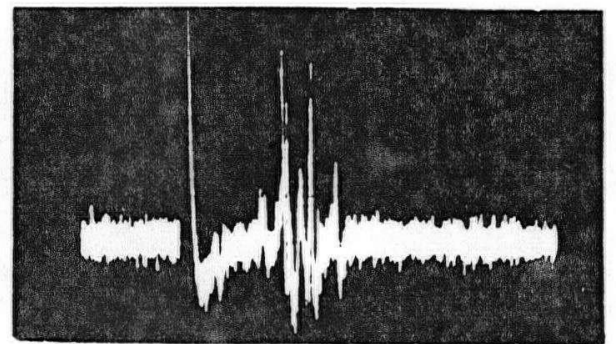

4 cortical Lesion $\stackrel{5}{5 \mathrm{msec} .}$

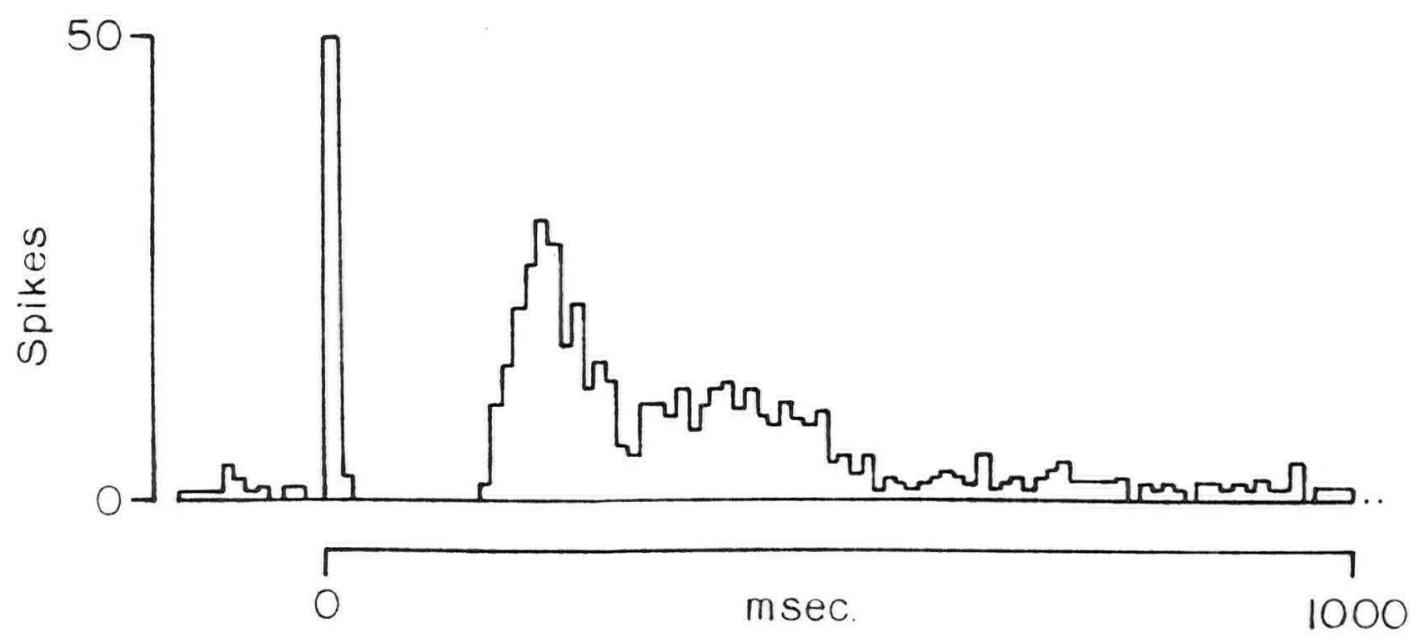


electrolytic lesion was placed in the IC using the already positioned stimulating electrode. Following the lesion, SN stimulation no longer elicited a burst response even after allowing one and one-half hours for recovery of tissue surrounding the lesion. Furthermore no responsive regions were detected during a subsequent careful search of the cd with the recording electrode (figure 6).

In three animals lesions of the ventro-medial tegmentum were made at the level of the $\mathrm{SN}$ and acute experiments vere performed 3 - 4 meeks later. Stimulation of the $D R N$ in these animals did not influence cd activity (figure 11).

A group of 6 animals had large electrolytic lesions placed in the region of the $\mathrm{SN}$. Pour veeks later acute experiments were performed. Stimulation of the IC of these animals produced a burst response in the ipsilateral cd (figure 14). Each tract of the recording electrode passed through several regions responding with a burst of excitation continuously present for 100 to 300 um. spontaneous or glutamate induced activity of both high and low amplitude units as inhibited for up to $300 \mathrm{msec}$. The characteristics of both the burst response and the inhibition vere identical to those observed in intact animals following stimulation of the IC or SN. However, in lesioned animals, high amplitude units were never evoked during the burst response. After each experiment the lesions were examined histologically and the dopamine 
EIGUEE 1ㄴ. Comparison of the burst response and inhibitory activity observed after stimulation of the $\mathrm{SN}$ (top) and IC (middle). Both sets of data were recorded from the same animal without adjusting the position of the recording electrode. on the right is a diagramatic cross section of a rat brain at the level of the hypothalamus. The dots indicate the region where capsular stimulation was effective in evoking a burst response. The response was blocked by electrolytic lesions of the IC destroying the region outlined by the dashed line. Bottom capsular stimulaticn still produces a burst and an inhibitory response in an animal with an electrolytic lesion of the $\mathrm{SN}$. The lesion was performed 4 weeks previons to the acute experiment. 


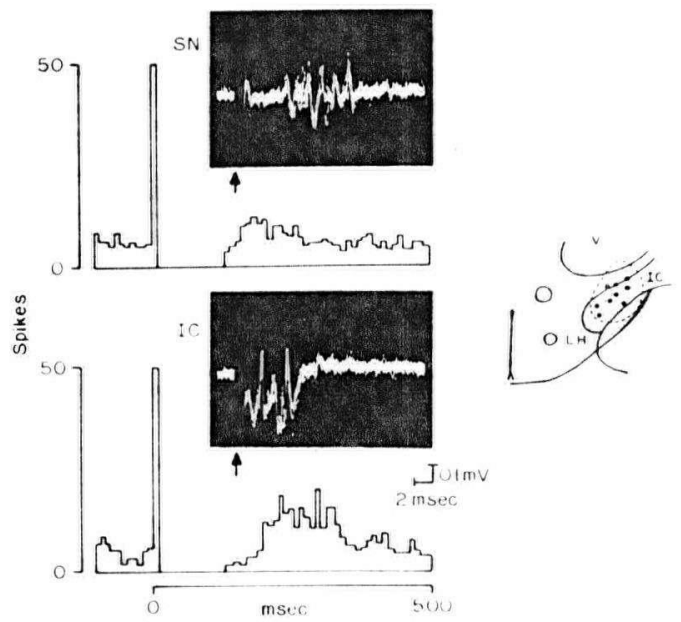

1C Stimuation (SN Lesion)

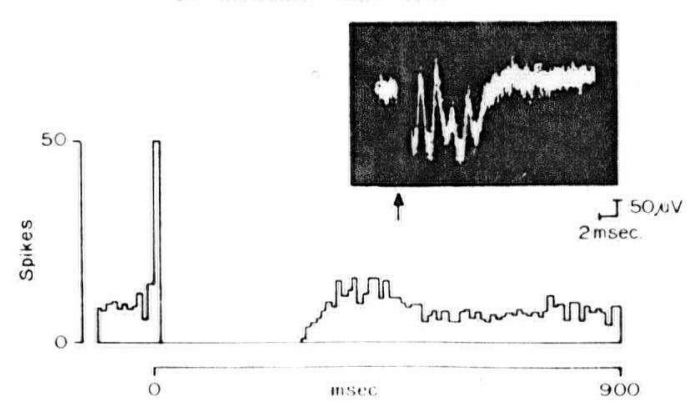


content of the ca was measured. In each animal the lesion bad resulted in a complete destruction of the $5 N$ as well as a depletion of $D A$ below detectable levels in the ipsilateral cd.

\section{Actions of Pharmacolologicaa Agents}

The intravenous injection of haloperidol 10.5 to $2.5 \mathrm{mg} / \mathrm{kg})$ or alpha-flupenthixol $(0.5$ to $2.5 \mathrm{mg} / \mathrm{kg})$ in 7 animals, and the iontophoretic application of alphaflupenthixol in 3 animals failed to influence either the burst response or the associated inhibition of sfontaneous activity (figure 15). However the same dose of intravenous haloperidol consistently blocked the high amplitude units evoked by nigral stimulation (figure 16). During the blockade even a maximal stimulus failed to evoke the unit although the unit would continue to respond antidromically to pallidal stimulation and the threshold for the burst and inhibitory response were unchanged. Recovery of the evoked response occurred 20 to 40 min after the intravenous injection. Six animals received unilateral injections of 6-OHDA into the nigrostriatal bundle. In later electrophysiological experiments there was no change in either the burst or inhibitory response to nigral stimulation. However high amplitude single units were never evoked. Following the acute experiment each cd was assayed for DA content. The injections were effective in depleting $D A$ levels in the ipsilateral ca by 90 to $95 \%$ when compared to the contralateral side. 
EIGURE 15: Influence of dopaminergic antagonism, or depletion, on the response recorded in the cd following stimulation of the SN. Intraveneous haloperidol $(1 \mathrm{mg} / \mathrm{kg}) \quad$ (A), iontophoretic application of alpha-flupenthixol (B), or previous chemical lesions of the medial forebrain bundle with 6-OHDA (C), did not influence either the inhibitory or excitatory response to nigral stimulation. 
A

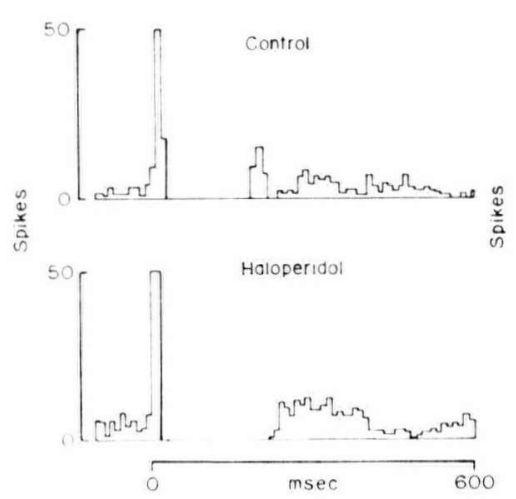

B.
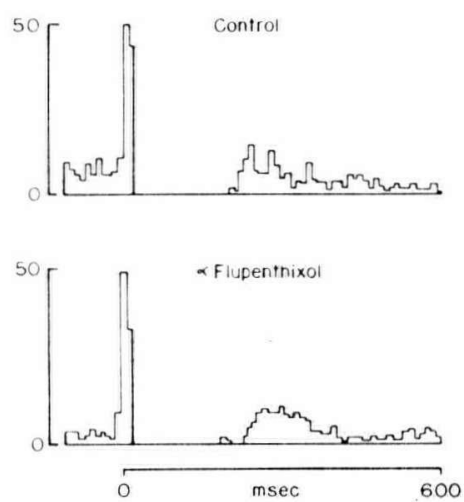

C

6-OHDA Lesion

FIGDEㅡ 16. Effect of intraveneous administration of haloperidol $(0.5 \mathrm{mg} / \mathrm{kg})$ on a large amplitude unit evoked by nigral stimulation. On the left stimuli were equal to threshold for this unit. on the right a stimulus intensity of twice threshold was used. Each photograph is of 5 superimposed sweeps of the oscilloscope. Note that haloperidol blocked the large amplitude unit even when the stimulus was applied at the higher intensity, although the burst response was not influenced. 

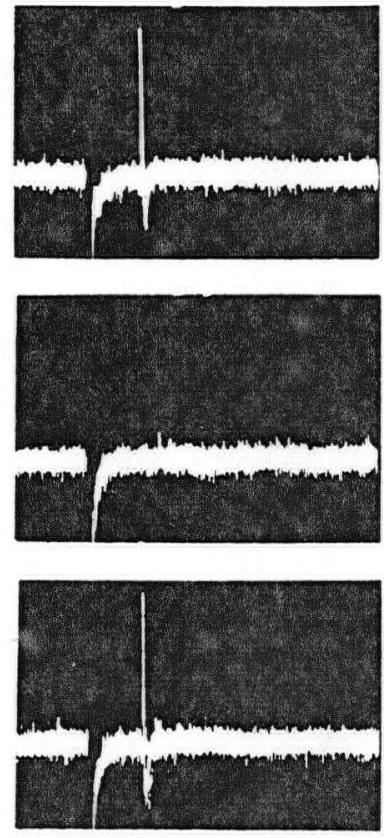

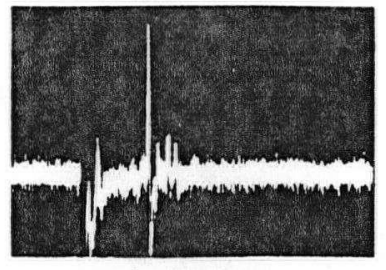

Control

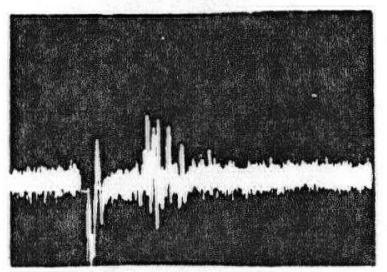

Haloperidol

( $3 \mathrm{~min}$ )

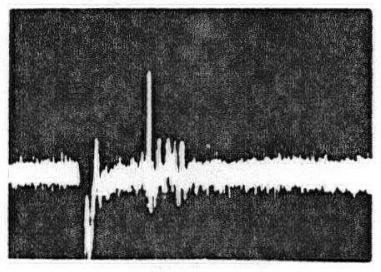

Recovery (20 min)

$$
\underset{10 \mathrm{msec}}{10.2 \mathrm{mv}}
$$




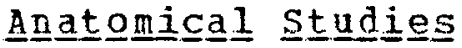

When injected into neuronal tissue, $\mathrm{ARP}$ is taken up by terminals and transported in a retrograde direction to cell bodies. Subseguent treatment for peroxidase activity will cause the formation of opaque granules in the soma and proximal dendrites of labelled cells. These can then be identified histologically by their stippled appearance under dark field illumination.

Five animals received a unilateral injection of $H R P$ in the $\mathrm{SN}$. Some diffusion of HRP occurred into the overlying tegmentum but the majority remained within the nucleus. Labelled cells were found mainly in the ventral aspect and "peripheral shell" of the cd. Very few were detected in the central core of the nucleus (figure 12). There were no differences in the distribution of labelled neurons in the cd following injection into the anterior or posterior extent of the SN.

Six animals received unilateral or bilateral injections of HRP into the Ca. The diffusion of HRP from the injection site was 1 imited to the boundaries of the cd and none was detected in the overlying cortex. Labelled cells were found in the cortex, pars compacta of the SN and in the IPT (figure 17). However there was also extensive labelling of cell bodies in the DRN along its entire anterior posterior extent (figure 18). The labelled cells were concentrated mainly in the region dorsomedial 
FIGURE 17 a diagramatic representation of labelled neurons in the IPT, zona compacta of the SN, and DBN, following injection of $\mathrm{BRP}$ into the Cd. HIPP, hippocampus; IL, intralaminar nucei of the thalamus; $P G$, periaqueductal grey matter; SNC, zona compacta of the substantia nigra; DRN, dorsal raphe nucleus; MRN, median raphe nucleus. 


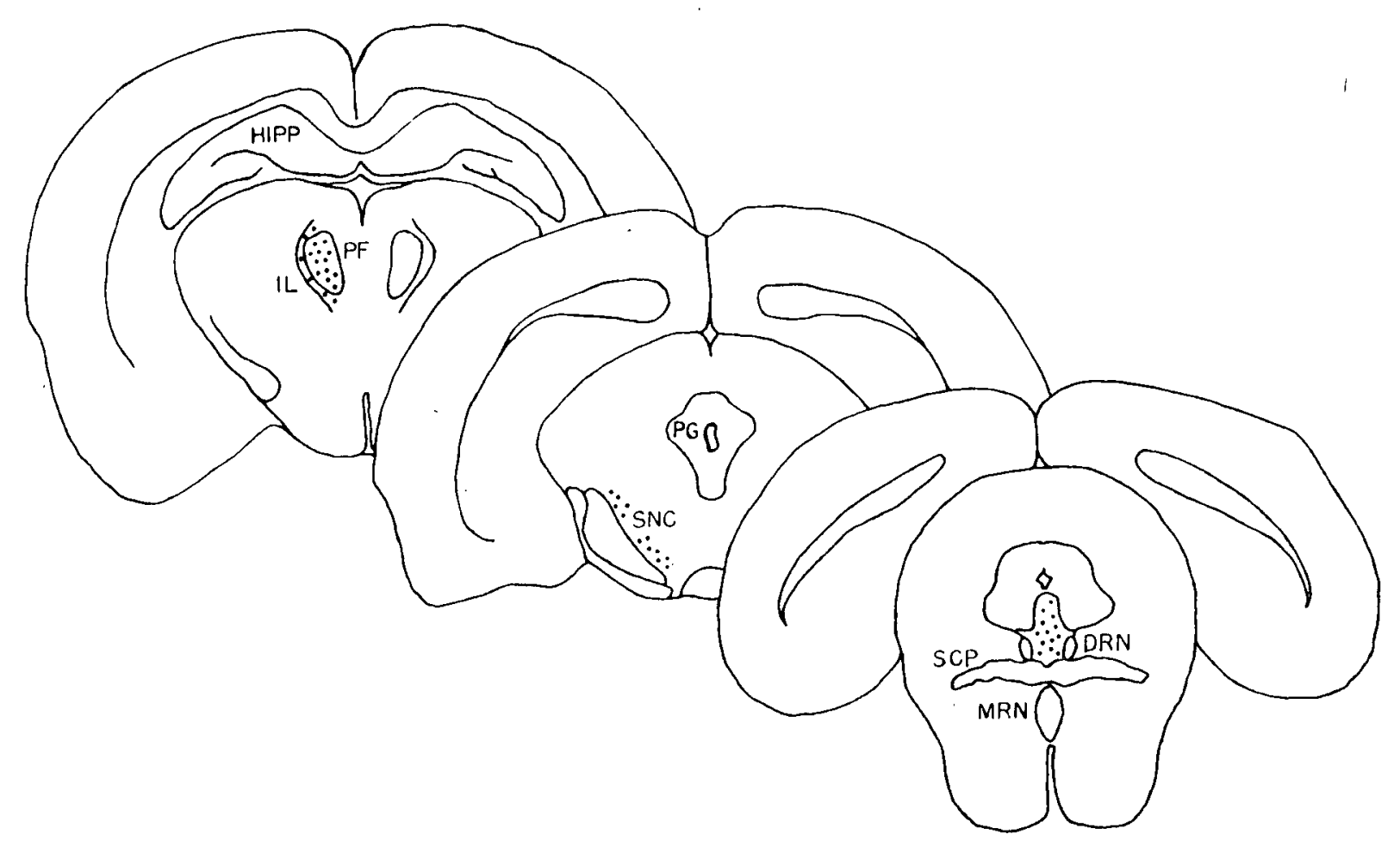


FIGUEE 18. Photomicrographs showing labelled neurons in the dorsal caphe nucleus following injection of HRP into the $C d$.

A) low power micrograph $(\times 40)$ following unilateral injection of 0.1 ul of HRP.

B) high magnification ( $\times 250$ ) following unilateral injection of 0.3 ul of $H R P$. Note the stippled appearance of the reaction product in somata and dendrites. Some cells are out of focus because of the thickness of the sections. CA, cerebral aqueduct; DRN, dorsal raphe nucleus; MLF, medial longidutinal fascicles. 
A.

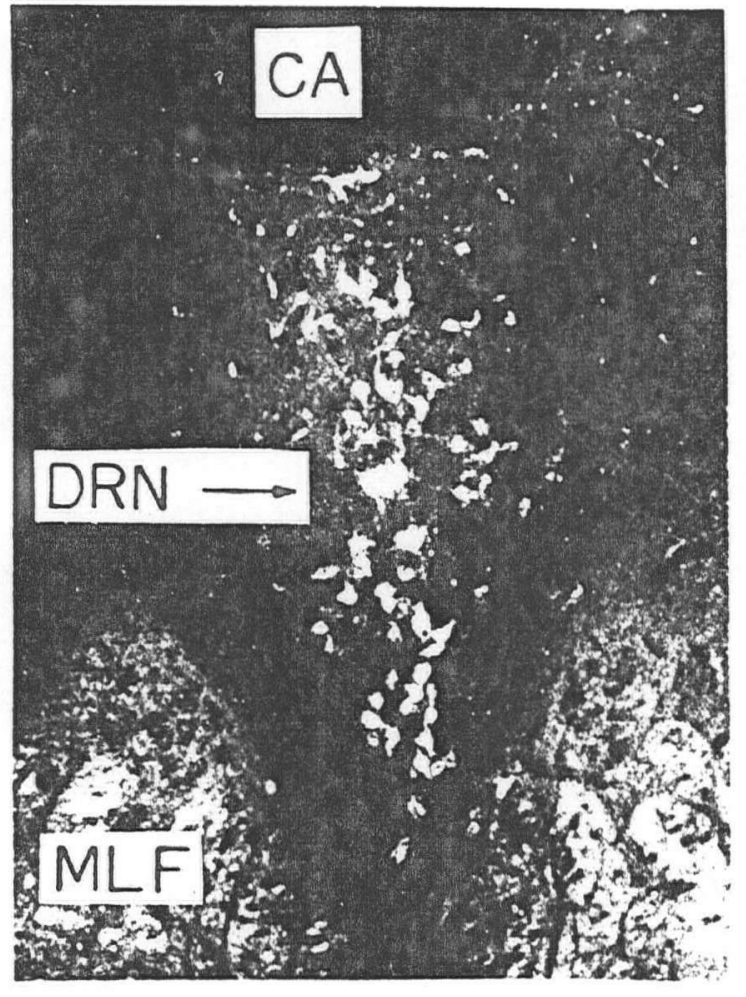

B.

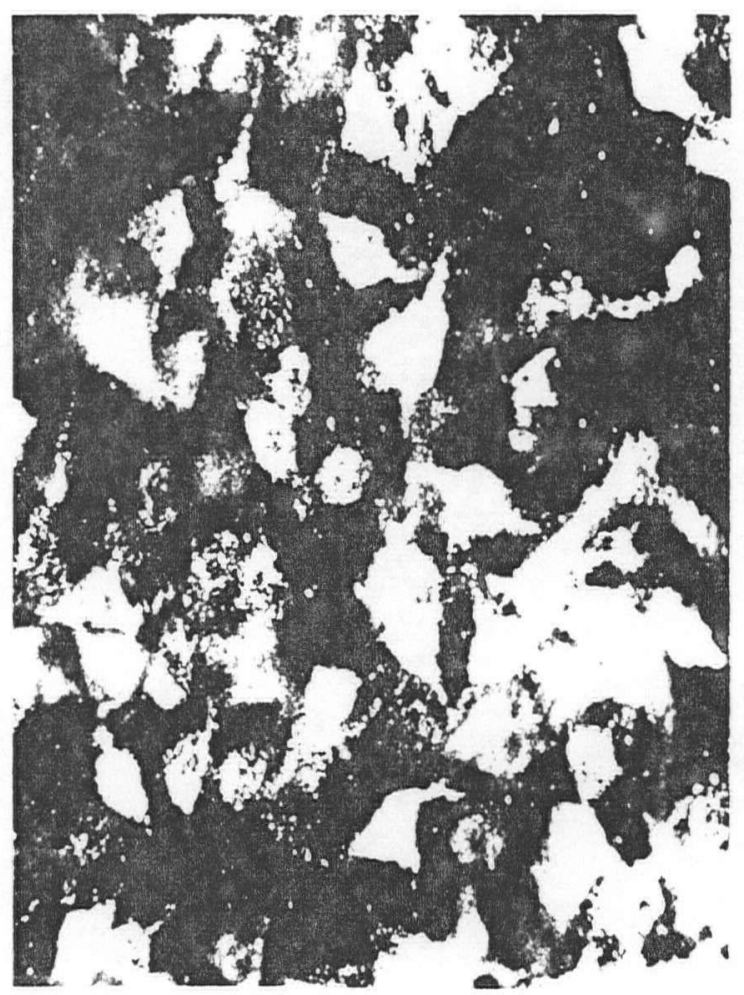


to the medial longitudinal fascicles. Some neurons were observed both dorsally in the periaguaductal grey matter and ventromedially in the nucleus linearis raphe. No labelled cells were observed in the median raphe.

orthograde axonal transport of protein from the raphe to the cd was also measured. Amino acids are actively taken up by the soma, incorporated into protein, and transported to the terminal of the neuron. In 5 animals unilateral electrolytic lesions were made in the medial forebrain bundle followed in 24 hours, by injection of tritiated leucine into the DRN. After an additional 24 hours significant levels of tritiated protein were found in both the ca and cortex of the intact side (table 1). The levels of radioactivity in samples from the lesioned side were $33.5 \%$ and $39.8 \%$ of the corresponding controls for the cd and cortex respectively. 


\section{TABBLE 1}

the effects of unilateral lesions of the medial forebrain bundle on accumulation of tritiated protein in the caudate nucleus and cerebral cortex after injection of tritiated leucine into the dorsal rapha nucleus.

Data represent mean $+-S . F . M$. from 5 rats

Control side

(disint./min/mg) lesioned side

(disint./min/mg) contr
Caudate nucleus

Cortex
$53.0+-9.2$

$17.8+-3.5$

$14.5+-0.9$

33.5

$36.4+-4.1$ 


\section{DISCUSSION}

previous investigators have emphasized the inhibition of striatal neurons observed following nigral stimulation. Since the firing of most striatal neurons is depressed by iontophoretic application of DA and DA is released in the cd following nigral stimulation, it has become generally accepted that $D A$ is an inhibitory transmitter in the striatum. However the present findings provide evidence for a different mechanism of inhibition and suggest that DA may function as an excitatory transmitter in the ni.grostriatal pathway.

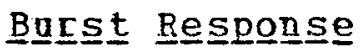

A burst of excitation was the predominant response evoked in the cd by nigral stimulation. The response was continuously observed over large displacements of the recording electrode. In many cases a movement of 300 4m was required to pass through an active region of striatum. However striatal neurons are usually only about 15 qu in diameter. Clearly, a single soma is not the neuronal structure responsible for generation of the burst response. On the other hand the fascicles of corticofugal fibers traversing the cd have a diameter of 50 to $200 \mathrm{qm}$. If nigral stimulation also activated axons in the pyramidal tract underlying the $S N$ the corticofugal fibers may have been antidromically activated. A burst of small potentials would then be recorded with an electrode 
located ithin a fascicle of fibers in the striatum. However, in the present experiments this explanation is unacceptable for the following reasons. A) Pontamine sky blue spots left by the recording electrode indicate that a burst response was recorded only in cellular regions of the striatum and never in a bundle of corticofugal fibers. B) Previous lesions of the cortex overlying the cd did not alter the burst response recorded during acute experiments. C) Stimulation of the pyramidal tracts slightly posterior to the sN did not evoke a burst response. D) The burst response did not follow nigral stimulation at frequencies above $50 \mathrm{~Hz}$. Fibers activated antidromically would follow much higher frequencies. E) Unlike axons, the neuronal structures underlying the response were sensitive to iontophoretically applied glutamate. Therefore, it is concluded that the burst response was recorded from either somata or dendrites of neurons synaptically excited by nigral stimulation.

The properties of the response suggest that it was generated by a cluster of neurons responding in a similar manner. Neurons near the electrode tip would contribute sharp spikes and the potentials Erom a large number of neurons at a greater distance from the tip would sumate to produce the "ripples" or waves of the baseline. As the electrode is moved short distances it would approach new cells and move away from others. The evoked potential would reflect the changing orientation of the electrode to the surrounding structures. New peaks would appear in the 
burst and others would decrease in size exposing an underlying field potential.

Regions responding with a burst of excitation were present throughout the $c d$. on each electrode tract several active regions vere detected. The neurons producing the response therefore must be very common. Several lines of reasoning indicate that the most likely candidate is the medium sized spiny cell described by kemp and Powell (1971 A). Firstly, they are the most numerous cell, making up $95 \%$ of the neurons in the striatum. Secondly, they have numerous dendritic branches extending 180-240 um aray from the parent cell. Thirdly, their axons usually terminate within the dendritic tree and therefore could influence nearby cells with a comon or overlapping dendritic field. Fina11y, these neurons are often observed in clusters (Chronister et al, 1976). Interaction between neurons within the cluster would account for the complex form of the burst response. 
Path way Mediating The Bu도는 Besponse

A response eroked by stimulation of a nucleus is often assumed to result from activation of somata near the tip of the electrode and subsequent activity in a pathway projecting from the nucleus to the recording site. However electrical stimulation of a region of brain can activate any neuronal structures in the vicinity of the stimulating electrode. For example, axons from a second nucleas projecting to the recording site may be activated if they pass near the stimulating electrode. However in the present experiments stimulation at sites slightly ventral, posterior or dorsal to the $\mathrm{SN}$ never produced excitation in the striatum. A burst response was only evoked when the stimulating electrode was accurately positioned in the $S N$. Therefore the response in unlikely to result from stimulation of "fibers of passage".

Nigral stimulation will also activate somata or axons projecting to regions of the brain other than the ca. since stimulation of the IPT also produced a burst response it is possible that nigral stimulation first activated thalamic neurons. They in turn may project to the cd and account for the burst of excitation. Similarly a polysynaptic pathway via the cortex may mediate the burst response. However neither of these mechanisms could account for the present findings since previous lesions of the IPT or ablation of the cortex overlying the cd did not influence the response to nigral stimulation. 
Nigral stimulation will also activate somata of nigrostriatal neurons. The dopamine released from the terminals of this pathway may excite striatal cells. However on the basis of the present experiments DA does not mediate the burst response. Neither haloperidol nor alpha-flupenthixol given systemically influenced the burst response. Iontophoretic application of alpha-flupenthixol was also without effect. Furthermore a chemical lesion of the dopaminergic neurons of the nigrostriatal pathway with 6-OHDA did not alter the burst response although striatal levels of DA were depleted to very low levels.

There remain two other possible explanations for the burst response. The response may be mediated by nondopaminergic nigrostriatal fibres. Alternately, nigral stimulation may activate terminals of the striatonigral and cause an antidromic activation of the cell bodies in the cd. Subsequent orthodromic activation of collaterals within the striaturn could then mediate the burst response. one method of differentiating between these two mechanisms is to lesion the $S N$, wait for orthograde degeneration of al1 fibres systems projecting from the $\mathrm{SN}$ to the cd and then stimulate along the pathay mediating the burst response. If the response is preserved the somata of the fibre system mediating the burst cannot lie in the SN.

The first step was to identify a site for stimulation along the pathway mediating the response. The striatonigral and nigrostriatal pathways both lie in the 
IC between the cd and SH. Stimulation of the IC anterior to the $S N$ produced a burst response in the $C d$. The similar properties of the response following nigral and capsular stimulation suggests that they may activate the same pathway. This was confirmed by finding that a discrete lesion placed in the IC by the already positioned stimulating electrode completely abolished the burst response following nigral stimulation. The response to capsular stimulation was then tested in animals with previous electrolytic lesions of the $5 N$. The nigral lesions did not influence the burst response recorded in the cd although the DA content of the ipsilateral cd of each animal was depleted to levels below those detectable by the assay procedure. clearly, the lesions had resulted in degeneration of the dopaminergic nigrostriatal pathway. Any other projection with cell bodies lying in the $S N$ would also have degenerated. Therefore the burst response evoked by nigral or capsular stimulation must be a result of an antidromic activation of the striatonigral pathwy with subsequent orthodromic activation of collaterals within the ca.

Antidromic potentials evoked by nigral stimulation were infrequently detected in the striatum and were only recorded from neurons in the "peripheral shell" of the nucleus. Retrograde transport of HRP from the SN also produced labelled cells exclusively in the peripheral shell of the $c d$. However the burst response was recorded throughout the structure. Therefore the neurons of the 
striatonigral pathway must give off large numbers of collaterals and many of these must terminate at long distances from the parent cell. Pallidal stimulation also evokes both antidromic and burst responses in the striatum. The antidromic potentials were more frequently detected than those evoked by nigral stimulation and were recorded almost exclusively in the central core of the striatum. The present investigation does not eliminate the possibility that the burst response was mediated through fibres of passage or through a polysynaptic pathway. However the striatum has a large projection to the GP and antidromic activation of these neurons may produce a burst response via collaterals of the striatopaliidal pathway. Kemp and Powell (1971A) described a medium sized and a "giant" projecting neuron. However, both cells are dispersed thronghout the nucleus and both have only a small number of collaterals near the soma. Based on the present experiments it is not clear which, if either, of these neurons may be the cells of origin for the striatonigral and striatopallidal pathways.

Other workers found that nigral stimulation evoked single units in the cd. Feltz and Albe-Fessard 1972;Frigyesi and Purpura 1973). The responses were not blocked by systemic haloperidol or lesicns of the nigrostriatal pathway. Intracellular studies also indicate that an EPSP is the first event evoked in striatal cells by nigral stimulation. In the present experiments nigral stimulation at low intensities evoked a burst response 
with only one or two spikes (see figure 1,7v). Perhaps some of the excitatory respones studied by other vorkers also result from an antidromic axon reflex mediated by the striatonigral pathway.

There are some inconsistencies in the literature regarding the antidromic responses of striatal neurons evoked by nigral stimulation. The latencies observed in the present study agree with those reported by Frigyesi and Purpura (1967) and York(1970). However other workers have reported antidromic responses with latencies in the range of 8 to 20 msec (Kitai et al. 1975; Liles, 1974). In the present study responses with these longer latencies invariably demonstrated all of the characteristics of an orthodromic response. They had variable latencies at threshold stimulation and failed at stimulus frequencies above $40 \mathrm{~Hz}$. 


\section{Inhibitorgy Response}

Spontaneously active neurons were only occasionally detected in the striatum. The activity of these neurons was completely inhibited for up to $300 \mathrm{msec}$ following nigral stimulation. Neurons activated by iontophoretic application of glutamate responded in a similar manner. The inhibitory response also occurred if the stimulating electrode was positioned slightly dorsal to the SN. Neurons of the mesencephalic raphe nuclei project through the ventral tegmentum near the $S N$ and are thought to terminate, in the striatum (Nauta et a1, 1974). Activition of these "fibres of passage" may have produced inhibition of striatal neurons. In the present study injection of HRP into the striatum produced a dense labelling of neurons specifically in the DRN and injection of tritiated leucine into the DRN resulted in a significant transport of tritiated protein to the cd. stimulation of the DRN produced inhibition of spontaneous and glutamate induced activity of striatal neurons for periods lasting up to 400 msec. Electrolytic lesions of the ventral tegmentum at the level of the $S N$ completely abolished the inhibitory influence of nigral stimulation and blocked the transport of tritiated protein.

These findings provide evidence for a raphe-striatal pathry. Axons of this pathway travel through or near the sN and could account for the inhibition of striatal units produced by nigral stimulation. However four weeks 
following electrolytic lesions of the DRN, nigral stimulation continued to produce inhibition of striatal units. Therefore a second mechanism of inhibition must be operating in the striatum.

The majority of striatal neurons are inhibited by the iontophoretic application of DA. Nigral stimulation is known to cause the release of DA from terminals of the nigrostriatal pathway and subsequently the DA could cause inhibition of striatal neurons. However dopaminergic blockade by systemic haloperidol or alpha-flupenthixol did not influence the inhibitory response. Chemical lesions of the nigrostriatal pathwa with 6-OHDA were also without influence although DA levels in the ipsilateral cd were depleted to very 1ow levels. Finally electrolytic lesions of the $\mathrm{SN}$ and subsequent degeneration of the striatonigral pathway did not alter the inhibition of striatal units produced by capsular stimulation. Cleacly, DA does not mediate the inhibitory influence of nigral stimulation. Furthermore lesions of the IPT or cortex did not influence the inhibitory response. These findings suggest that the cells excited by collaterals of the striatonigral pathway are in fact inhibitory interneurons. Several findings support this hypothesis. A) A spontaneous unit inhibited by nigral stimulation and a burst response vere usnally recorded simultaneously from the same electrode site. B) As the stimulus intensity was slow 17 increased from zero the onset of inhibition coincided with the development of the burst. C) A stialus intensity sufficient to produce a 
maximal burst also produced a maximum inbibition. D) If additional application of glutamate caused degeneration of the burst the inbibition was abolished.

spontaneously active or glutamate induced units in the striatum could be differentiated into two populations on the basis of amplitute. The majority had a low amplitude. Often threshold stimulation of the $\mathrm{SN}$ evoked a low amplitude spike at a constant latency. As the stimulus intensity was increased the unit became incorporated into the burst response. The spontaneous activity of the same cell would then be inhibited following each burst. This finding suggests that the inhibitory interneurons have reciprocal synaptic connections. Therefore if the medium sized spiny cells are the inhibitory interneurons, they should receive both excitatory and inbibitory synaptic contacts. Kemp and Powell (1971B) found that the spiny cells receive synaptic input from other neurons within the cd. These synapses have membrane specializations associated with both excitation (Golgi type 1, Gray, 1959) and inhibition (Golgi type 2). 


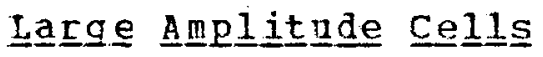

The second population of spontaneous units had amplitudes distinctly greater than the burst resfonse. They responded to nigral stimulation with a single orthodromic action potential. Usually a burst response was evoked at the same recording site. However the high amplitude units could be differentiated from the underlying burst by their greater amplitude, lower threshold and single action potential. Spontaneous activity of these units was also inhibited following the burst response. In fact, as the stinulus intensity was increased to produce a maximal burst the high amplitude unit often failed to respond (fig 10 , a). This suggests that the influence of the inhibitory interneuron was sufficient to overcome the synaptic excitation produced by nigral stimulation.

Unlike other responses to nigral stimulaticn, large amplitude units were detected only in the central core of the striatum. The same units were antidromically activated by pallidal stimulation. Therefore they may be striatopallidal neurones.

The present experiments indicate that the large amplitude units were activated by the dopaminergic nigrostiatal pathway. Systemic haloperidol reversibly blocked the response, the response was not detected in animals with previous chemical lesions of the dopaminergic nigrostriatal pathway, and capsular stimulation did not 
evoke the response in animals with lesions of the $5 \mathrm{~N}$.

\section{Concluㅗion}

In contrast to earlier reports, the present findings do not support the hypothesis that DA mediates the inhibition of striatal neurons following nigral stimulation. In fact the nigrostriatal patbray may excite specific neurons in the striatum. However, an important question remains. If $D A$ is an excitatory transmitter by what mechanism does iontophoretic application of DA produce inhibition in the majority of neurons. Two possible explainations can be considered. Firstly, York (1970) has suggested that striatal neurons may possess two types of DA receptors, one excitatory and one inhibitory in function. The excitatory receptor may be specifically located in dopaminergic synapses whereas the inhibitory receptors may be located on other regions of the cell. secondly, the initial response to iontophoretically applied DA may be excitation. However, continued application over a period of longer than a few hundred msec may produce a pharmacological "overload" of the receptors resulting in a non-physiological depression of the neuron. Kitai (1976) recorded the intracellular response to extracellular application of DA. He found that very short pulses lasting only a fraction of a second consistently produced an EPSP.

In conclusion the present experiments have 
demonstrated that nigral stimulation activates at least two pathways (figure 19). Stimulation of the nigrostriatal pathway excites neurons of the striatopallidal pathway. Nigral stimulation also antidromically activates the striatonigral pathray and its collaterals within the cd. Inhibitory interneurons excited by these collaterals inhibit the activity of both striatopallidal neurons and low amplitude units. At least some of the low amplitude units may also be inhibitory interneurons. Finally a raphe striatal pathway exists and stimulation of this pathway causes a direct inhibition of striatal units 
EIGUEㅡ 19. A schematic illustration of the proposed synaptic arrangements of striatal neurons (Cd) with those of the substantia nigra (SN) and globus pallidus (GP). Stimulation of the zona compacta of the SN (SNC) produces an activation-inhibition sequence of striatal target cells. The inhibitory component is mediated by recurrent axon collaterals impinging on inhibitory interneurons (shown in black). Stimulation of the GP elicits antidromic spikes in the same axon collateral system. Stimulation of the zona reticulata of the SN (SNR) evokes an antidromic response mediated by the striato-nigral pathwa and inhibition of cd target cells by recurrent collaterals impinging on inhibitory interneurons. 


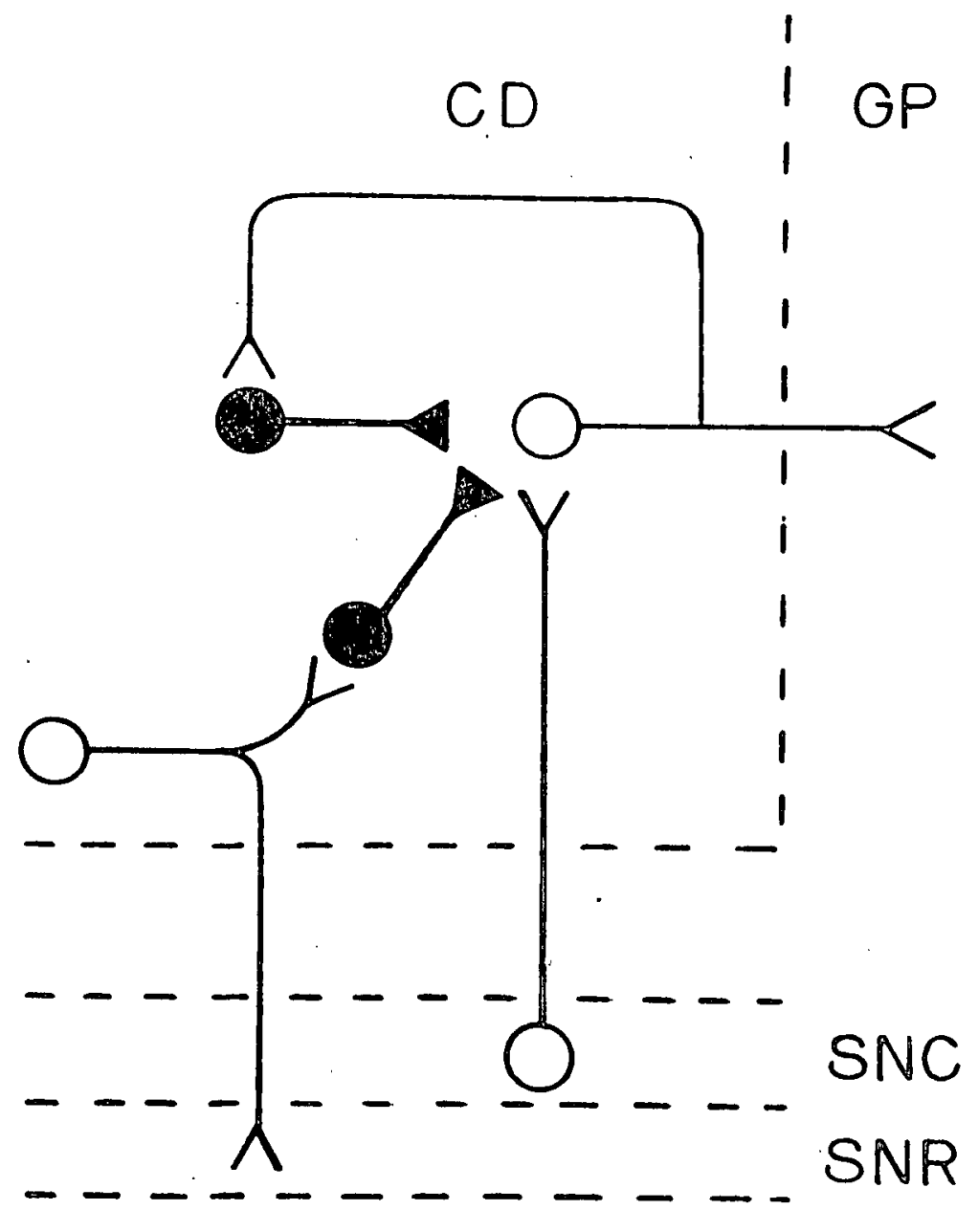




\section{BEEFEEREENCES}

ANDEN, N. R., DAHLSTRÖM, A., FUXE, K., LARSSON, K., OLSON, L. AND UNGERSTEDT, U. (1966) Ascending Monoamine Nencones To The Telencephalon And Diencephalon



AGHAJANIAN, G. K., KUHAR, M. J. AND ROTH, R. H. (1973) Serotonin-containing Neuronal perikarya And Terminals: Differential Effects of P-

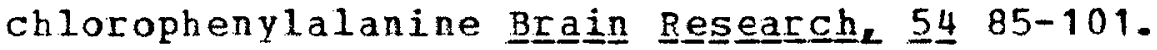

BAXTER, C. G., AND ROBERTS, E. (1959) Elevation of Gammaaminobutyric Acid In Rat Brain

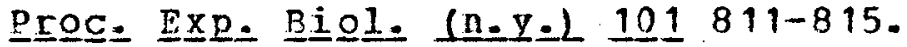

BERTLER, A. AND ROSENGREN, E. (1959B) On The Distribution In Brain of Monoamines And of Enzymes Responsible For Their Formation Exxperientia. 15382 .

BERTLER, A. AND ROSENGREN, E. (1959A) Occurrence And Distribution of Dopamine In Brain And other Tissues Experientia, 15 10-11.

BLOOM, F.E., COSTA, E., AND SALMOIRAGHI, G. C. (1965) Anesthesia And The Responsiveness of Individual Neurons of The Caudate Nucleus of the Cat To Acetylcholine, Norepinephrine And Dopamine Administered By Microelectrophoresis 글 hㅡ므므므으. Exp= Ther.. 150, 244-252.

BOGDANSKI, D. F., ĐEISSBACH, H., AND UDENFRIEND, S. (1957) The Distribution of Serotonin, 5-hydroxytryptophan Decarboxylase, And Monoamine oxidase In Brain I Neurcochem=e $1272-278$.

BROCH, O. J. AND MARSDEN, C. A. (1972) Regiona 1 Distribution of Monoamines In The corpus striatum of The Rat. Brain Researche 38 425-428. 
BUCHGALD, N. A., PRICE, D. D., VERNON, L. AND HULL, C.D. (1973) Caudate Intracellular Response To Thalamic

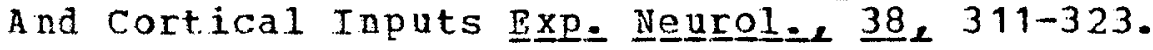

BUCHWALD, N. A., WYERS, E. J., CARLIN, J. AND FARI.EY, R. E. (1961a) Rffects of caudate stimulation on Visual Discrimination Exp. Neurrol.e 4 23-26.

BUCHUALD, N. A.. WYERS, E. J.. LAOPRECHT, C. W. AND HEUSER, G. (1961b) The Caudate-spindle IV: A Behavioral Index of caudate Induced Inhibition

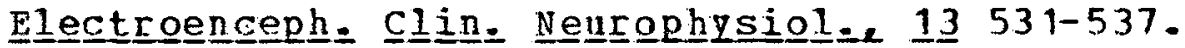

BUTCHER, L. J. AND BILEZIRJIAN, L. (1975) Acetylcholinesterase containing Neurons In The Neostriatum And Substantia Nigra Revealed nfter Punctate Intracerebral Injection of Di-isopropyl

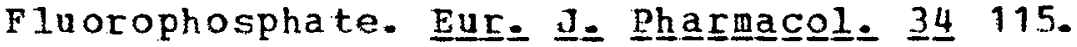

BUTCHER, L. L. AND HODGE, G. (1976) Postnatal Development of Acetylcholinesterase In The caudate-putamen Nucleus And Substantia Nigra of Rats Briaiㅡ Research, 106 22.3-240.

BOTCHER, L. L., TALBOT, K., AND BILEZIKJIAN, L. (1975) Localization of Acetylcholinesterase within Dopamine Containing Neurons In The Zona Compacta

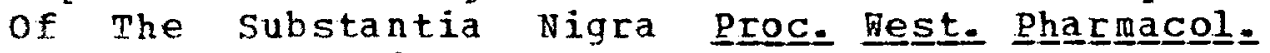
S으드= $1 \underline{8}$ 256-259.

CAJAL, S. AND RAMON, Y. (1911) Histologie Du systeme Nerveaux De L'Homme Et Des Vertebres, 므는 II Maloine, Paris. $504-514$.

CARLSSON, A. (1959) The occurrence, Distribution And physiological Role of Catecholamines In the

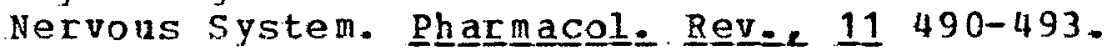

CARMAN, J. B., COWAN, H. M. AND PONELL, T. P. S. (1963) The Organization of Corticostriate connexions In The Rabbit B드르. 
CARMAN, J. B., COHAN, U. M., AND HEBSTER, K. E. (1965) A Bilateral Cortico-striate Projection J. Neurol.

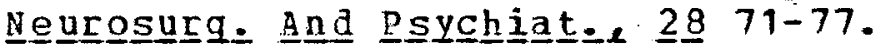

CARPENTER, M. B. AND STROMINGER, N. L. (1967) Efferent Fibers of the Subthalamic Nucleus In The Monkey. A Comparison of The Efferent projections of The Subthalamic Nucleus, Substantia Nigra And Globus

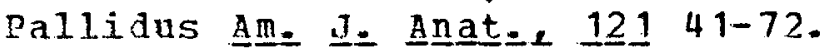

CHRONISTER, R. B. FARNELL, K. E., MARCO, L. A. AND HHITE, L. E. JR. (1976) The Rodent Neostriatum: A

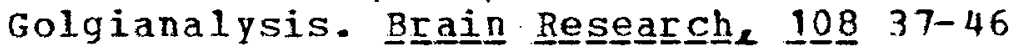

CONNOR, J. D. (1968) Caudate Unit Responses To Nigral Stimuli: Evidence For A Dossible Nigro-neostriatal Pathway Science, 160 899-900.

CONNOF, J. D. (1970) Caudate Nucleus Neurones: Correlation of The Effects of Substantia Nigra stimulation


2묘 $691-703$.

CONNOB, J. D. (1975) Electrophysiology of The Nigrocaudate Pathway pharmacool. Ther=1 1 357-370.

CONRAD, L. C. A.. LEONARD, C. M. AND PFAFF, D. W. (1974) Connections of The Hedian And Dorsal Raphe Nuclei In The Rat: An Autoradiographic And Degeneration study I. Comp. Neurgol=e $15 \underline{6}$ 179-205.

CORZON, G. AND GREEN, A. R. (1970) Rapid Method For the Determination of 5-hydroxtryptamine And 5hydroxyindoleacetic Acid In Small Regions of Rat Brain Brit. I. Pha

DAHLSTRÖM, A. AND FUXE, K. (1964) Evidence For The Existence of Monoamine-containing Neurons In The Central Nervous system. I Demonstration of Monoamines In The Cell Bodies of Brain Stem

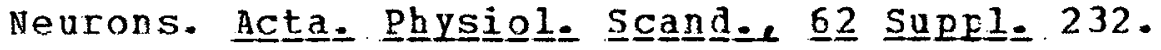


DAHLSTRÖM, A., HAGGENDAL, J. AND ATACK, C. (1973) Localization And Transport of Serotonin In J. Barchas And E. Usdin (eds.) Serotonin And

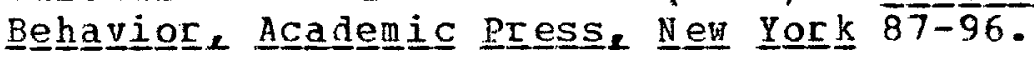

DENNY-BROWN, D. (1962) The Basal Ganglia And Their Relationship To Disorders of Movement oxforgd

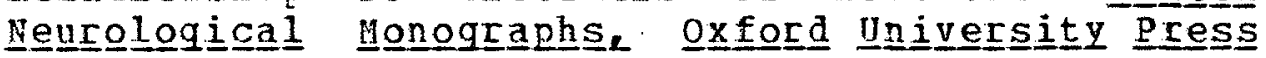
Lond므므 -

DUFFY, M. J., MULHALL, D., AND POWELL, D. (1975) Subcellular Distribution of Substance $p$ In Bovine Hypothalamus And Substantia Nigra I. Neurochem=e 2. $305-307$.

EHRINGER, H. UND HORNYKIEWICZ, O. (1960) Verteilung Von Noradrenalin Und Dopamin (3-Hydroxytramin) Im Gehirn Des Menschen Und IhI Verhalten Bei Frkrankungen Des Extrapyramidalen systems. Kling 보도드. $\underline{3}$ 8 1236-1239.

ENNA, S. J., FUHAR, M. J., AND SNYDER, S. H. (1975) Regional Distribution of Postsynaptic Receptor Binding For GABA In Monkey Brain Br 23 168-174.

FAHN, S. AND COTE, L. J. (1968) Regional Distribution of Gamma-aminobutyric Acid (GABA) In Brain of Rhesus

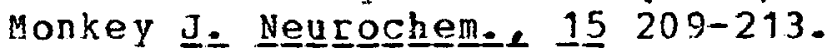

FALCK, B., HILLARP, N. A., THIEME, G. AND THORP, A. (1962) Fluorescence of Catecholamines And Related Compounds Condensed From Formaldehyde $\underline{J}_{-}$

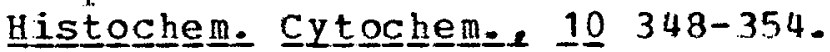

FELTZ, P. AND ALBE-FESSARD, D. (1972) A study of An Ascending Niqro-caudate Pathway Electroenceph.

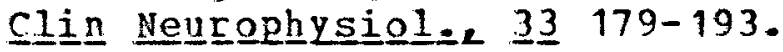

FELTZ, P. AND DECHAMPLAIN, J. (1972) Persistence of Caudate Unitary Responses To Nigral Stimulation After Destruction And Functional Impairment of The Striatal Dopaminergic Terminals Braiㅡㄹ Researche 43 595-600. 
FEITZ, P. AND MACKENZIE,J. S. (1969) Properties of Caudate Unitary Responses In Repetitive Nigral stimulation

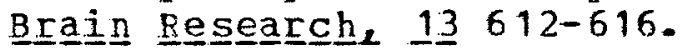

FELTZ, P. (1970) Dopamine, Amino Acids And Caudate Unitary

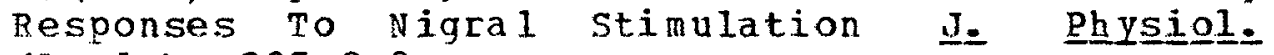

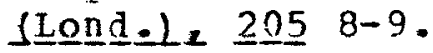

FELTZ, P. (1971) Sensitivity To Haloperidol of Caudate Neurones Excited By Nigral Stimulation Euㄷㅇㅇ. ․ㅡ

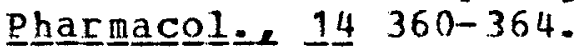

FERRIER, D. (1873) Experimental Researches In Cerebral Physiology And Pathology West Riding Lunatie As $y \underline{1}$ uㅡㅁㅡ Medical Reports, 30 .

FIBIGER, H. C., PUDRITZ, R. D., MCGEER, R. L. AND MCGEER, E. G. (1972) Axonal Transport In Nigro-striata 1 And Nigro-thalamic Neurons: Effects of Medial Forebrain Bundle Lesions And 6-hydroxydopamine ${ }^{-}$ Neugrochem.e 19 1697-1708.

FLOREY, E. (1960) Physiological Evidence For Naturally occurring Inhibitory Substances. Inhibition In The Nervous System And GABA-aminobutric Acide Ed. E-

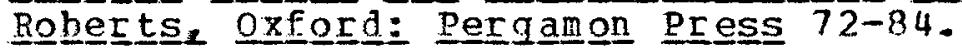

FORMAN, D., AND AARD, J. D. (1957) Responses To Electrical Stimulation of Caudate Nucleus In Cats In Chronic

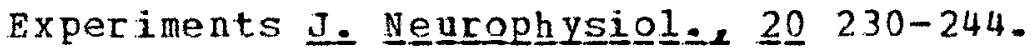
FRIGYESI, T. I. AND PIRPURA; D. P. (1967) Electrophysiological Analysis of Reciprocal

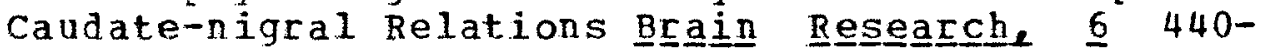 456.

FULLER, D. R. G., HULL, C. D. AND BUCHHALD, N. A. (1975) Intracellular Responses of Caudate output Neurons To orthodromic stimulation Braiㅡㄹ 트search. 96 337341. 
GERSTEIN, G. AND KIANY, N. S. (1960) An Approach To The Quantitative Analysis of Electrophysiological Data From Single Neurons Biophysical Journall 1 15-28.

GONZALEZ-VEGAS, J. A. (1974) Antagonism of Dopaminemediated Inhibition In The Nigro-striatal Pathway: A Mode of Action of Some Catatonia-inducing Drugs

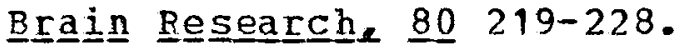

GRAHAM, R. C. AND KARNOVSKY, M. J. (1966) The Early Stages of Absorption of Injected Horseradish peroxidase In The Proximal Tubules of Mouse Kidney: 01trastructural Cytochemistry BY A New Technique J. Histochenem Cytochem=. 14 291-302.

GRAY. E. G. (1959) Axo-somatic And Axodendritic Synapses of The Cerebral Cortex: An Electron Microscope Study. I = Anat.e Londone $\underline{9} \underline{3}$ 420-423.

HEATH, R. G. AND HODES, R. (1952) Induction of sleep By Stimulation of The Caudate Nucleus In Macaqus

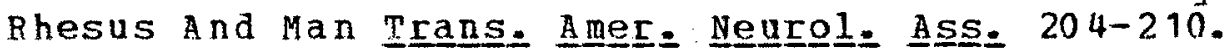

HENDLEY, C. D. AND HODES, R. (1953) Effects of Lesions on Subcortically Evoked Movement In Cat I.

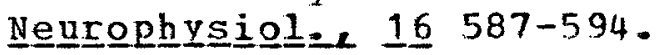

HERZ, A. AND ZIEGLGANSBERGER, W. (1968) The Influence of Microelectrophoretically Applied Biogenic Amines, Cholinomimetics and procaine on synaptic Excitation In The corpus Striatum Int. I.

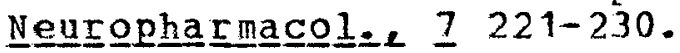

HESS, W. R. (1948) Korrespondierend symptome Aus Stirnhirn. Innerer Kapsel Und Vorderem Thalamus

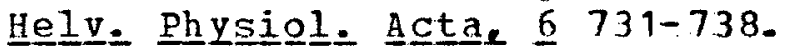

HINMAN, A. AND CARPENTER, M. B. (1959) Efferent Fibre Projections of The Red Nucleus In The Cat.

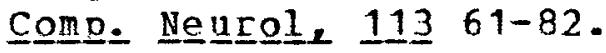


HOCKFELT, T.. KELLERTH, J. OL, NILSSON, G., AND PERNOW, B. (1975) Substance $\mathrm{P}$ Localization In The central Nervous system and In Some Primary Sensory Neurons Sciencel $190 \quad 889-890$

HOLMAN, R. B. AND VOGT, M. (1972) Release of 5hydroxytryptamine From Caudate Nucleus And septum

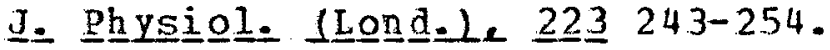

HULL, C. D., BERNARDI, G. AND BUCHWALD, N. A. (1970) Intracellular Responses of Caudate Neurons To

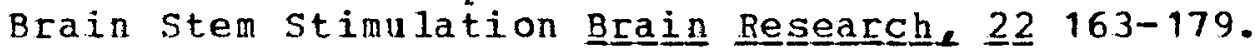

HULL, C. D., BERNARDI, G., PRICE, D. D., AND BUCHHALD, N. A. (1973) Intracellular Responses of Caudate Neurons To Temporally and spatially combined

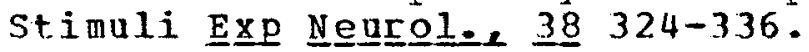

HULL, C. D., LEVINE, M. S., BUCHHALD, N. A., HELLER, A. AND BRONNING, R. A. (1974) The Spontaneous Firing pattern of Forebrain Neurons. I. The Effects of Dopamine And Non-dopamine pepleting Lesions on

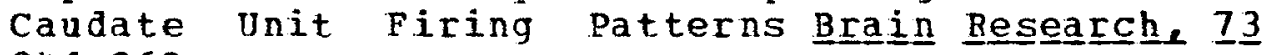
241-262.

HUNTER, J. AND JASPER, H. (1949) Effects of Thalamic Stimulation In Unanesthetized Animals $\underline{E}_{-}=\underline{G}=\underline{G} \underline{1} \underline{\underline{n}}=$ Neurophysiole 1 . 305-324

JANSEN, J. AND JANSEN, J. 1955 on the Efferent Fibres of The Cerebellar Nuclei of the Cat J. Comp. Neurolol-2 $102607-632$.

JUNG, R., AND HASSLER, R. (1960) The Extrapyramidal Motor System In J. Field =ed.e Handbook of physiolology. Section I, neurophysiology, Vol- $\underline{1}_{2}$ The A merican

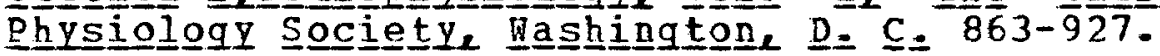

KANAZARA, I., AND JESSEL, T. (1976) Postmortem Changes And Regional Distribution of substance $P$ In The Rat

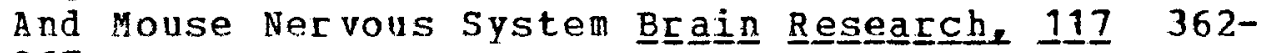
367. 
KEMP, J. M. AND POWELL, T. P. S. (1971a) The Structure of The Caudate Nucleus of The Cat: Light And Electron

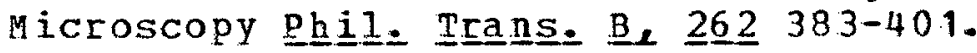

KEMP, J. M. AND POWELL, T. P. S. (1971b) The synaptic organization of The Caudate Nucleus Phil. Trans. B. $\underline{2} \underline{6} \underline{2} 403-412$.

KEMP, J. M. AND POHELL, T. P. S. (1971c) The connexions of The striatum and Globus Pallidus: Synthesis And

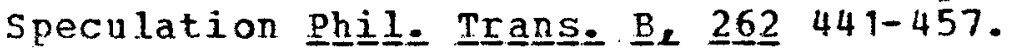

KEMP. J. M. (1968) Observations on The Caudate Nucleus of The Cat Impregnated With The Golgi Method Braiin Reseeㅡㄷㅡ. $11 \quad 467-470$.

KEMP, J. M. (1970) The Termination of Strio-pallidal And

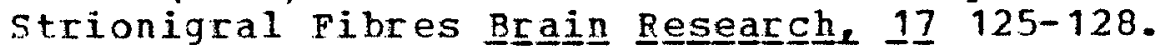

KIM, J. S., BAK, I. J., HASSLER, R. AND OKADA, Y. (1971) Role of Gamma-aminobutyric Acid (GABA) In The Extrapyramidal Motor system 2. Some Evidence For The Existence of A Type of GABA-rich Strio-nigral

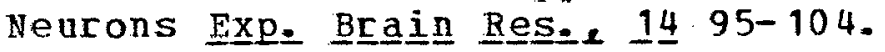

KIM, J. S., HASSLER, R., KUROKAWA, M., AND BAK, I. J. (1970) Abnormal Movements And Rigidity Induced By Harmaline In Relation To striatal Acetylcholine,

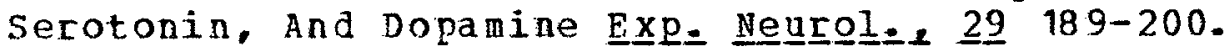

KITAI, S. T., SUGIMORI, M. AND KOESIS, J. D. (1976) Excitatory Nature of Dopamine In The Nigro Caudate

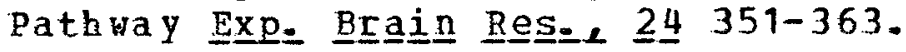

KITAI, S. T., HAGNER, A., PRECHT, W. AND OHNO, T. (1975) Nigrocaudate And Caudato-nigral Relationship: An Electrophysiological study Braiㅡ Research. 85 4448.

KONIG, F. C. AND KLIPPEL, R. A. (196.3) The 를 Braing

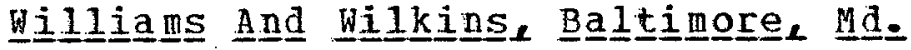


KOSTOWSKI, T., GIACALONE, E., GARATTINI, S. AND VALZELII, L. (1968) Studies on Behavioural And Biocherical Changes In Rats After Lesions of Midbrain Raphe

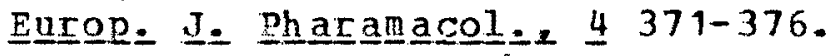

KRNJEUIC, K. AND PHILLIS, J. W. (1963) ACtions of Certain Amines on Cerebral Cortical Neurones. Brit. Phaamacolol.. 므 $471-490$.

KUHAR, M. H., ROTH, R. H., AND AGHAJANIAN, G. K. (1971) Selective Reduction of Tryptophan Hydroxylase Activity In Rat Forebrain After Midbrain Raphe Lesions Brain Researche 35 167-176.

KUHAR, M. J. , AGHAJANIAN, G. K. AND ROTH, R. H. (1972) Tryptophan Hydroxylase Activity And Synaptosomal Jptake of Serotinin In Discrete Brain Regions After Midbreain Raphe Lesions: Correlations With Serotonin Levels And Histochemical Fluorescence Braaiㅡ Resea

KUYPER, H. G. J. M. , KIEVIT, J. AND GROEN-KLEVANT, A. C. (1974) Retrograde Axonal Transport of Horseradish Peroxidase In Rat's Forebrain Braiㅡㅡ Research 211-218.

LA VERTY, R. MICHAELSON, I. A., SHARMAN, D. F. AND WHITTAKER, $\quad$. P. (1963) The Subcellular Localization of Dopamine And Acetylcholine In The

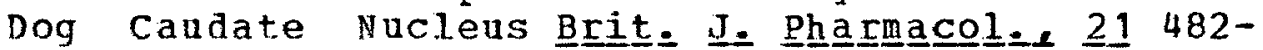
490 .

LEVINE, M. S., HOLL, C. D. AND BUCHWALD, N. A. (1974) pallidal And Entopeduncular Intracellular Besponses To Striatal, Cortical, Thalamic And Sensory Inputs Exp= Neurol=2 44 448-460.

LILES, S: I. (1974) Single Unit Responses of Caudate Neurons To stimulation of The Frontal Cortex, Substantia Nigra And Entopeduncular Nucleus In

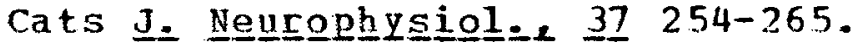


LINDVALL, O. AND BJORKLUND, A. (1974) The organization of The Ascending Catecholamine Neuron systems In The

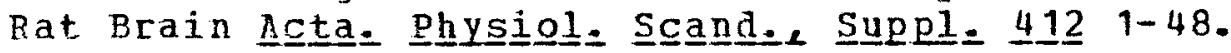

LORENS, S. A. , AND GULDBERG, H. C. (1974) Regional 5hydroxytryptamine Following selective Midbrain Raphe Lesions In the Rat Braiin Research. 78 45-56.

LOWE, I. P., ROBINS, E. AND EYERMAN, G. S. (1958) The Pluorometric Measurment of Glutamine Decarboxylase And Its Distribution In Brain J. Neucochem.e 3 818.

MCGEER, E. G. AND MCGEER, P. L. (1962) Catecholamine Content of spinal cord canadian J. Biochem.

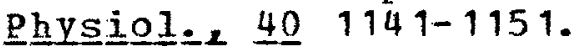

MCGEER, E. G. WADA, J. A., TERAO, A. AND JUNG, E. (1969) Amine Synthesis In Various Brain Regions Hith Caudate Or Septa1 Lesions. Exp. Neurole $\underline{2}$. $277-$ 288 .

MCGFER, P. L., FIBIGER, H. C., MALER, L., HATTORI, T. AND MCGEER, E. G. (1974) Evidence For Descending Pallido-nigral GABA Containing Neurons Aduaㅡㄹㅗ $I \underline{n}$

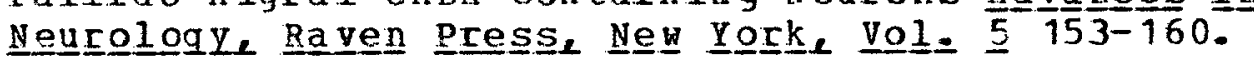

MCLENNAN, H. AND YORK, D. H. (1967) The Action of Dopamine on Neurones of The Caudate Nucleus J. Physiol. SLond.le 189 393-402.

MCLENNAN, H., EMMONS, P. R. AND PLUMMER, P. M. (1964) Some Behavioral Effects of Stimulation of The Caudate Nucleus In Unrestrained Cats Canadian $\underline{J}$. of

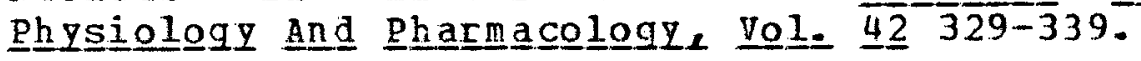

MAJAMUD, N.. BIRANO, A. (1974) Altas of Neuropatholology,

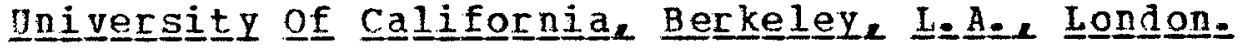

MALER, L., FIBIGER, H. C. AND MCGEER, P. L. (1973) Demonstration of The Nigrostriatal projection By Silver Staining After Nigral Injections of 6-

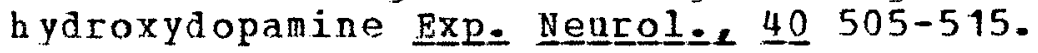


MALLIANI, A. AND PURPURA, D. P. (1967) Intracellular Studies of The Corpus striatum. II patterns of Synaptic Activities In Lenticular And

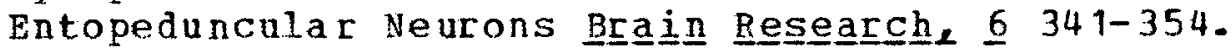

MCGEER, P. L., MCGEER, E. G. FIBIGER, H. C. AND HICKSON, V. (1971) Neostriatal Choline Acetylase And Acetylcholinesterase Following selective Brain Lesions. Brrain Researchhe $\underline{3} \underline{5}$ 308-314.

METTLER, F. A. (1944) The Tegmento-olivary And Central

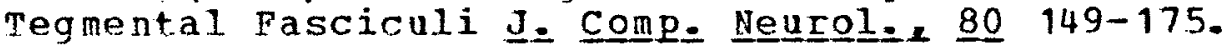

MILLER, J. J., RICHARDSON, T. L,, FIBIGER, H. C. AND MCLENNAN, H. (1975) Anatomical And Blectrophysiological Identification of A Projection Erom The Mesechephalic Raphe To The

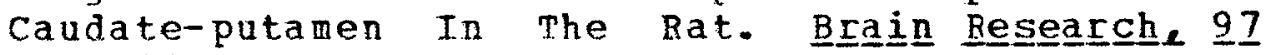
$133-138$.

MOORE, R. Y.. BHATNAGA, R. K. AND HELLER, A. (1971) Anatomical And Chemical Studies of $A$ Nigroneostriatal projection In The Cat Bräin Researche 30 $119-135$.

NAUTA, H. J. W., PRITZ, H. B., AND LASEK, R. J. (1974) Afferents To The Rat Caudoputamen studied ith Horseradish Peroxidase. An Evaluation of A Retrograde Neuronanatomical Research Method Bㄷaiㅡ Researche 6ㄱ 219-238.

NAUTA, H. J. H. AND MEHLER, W. R. (1966) Projections of The Lentiform Nucleus In The Monkey Braing

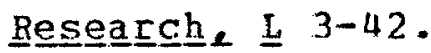

OHYE, C., BODCHARD, R., BOJCHER, R. AND POIRIER, L. J. (1970) Spontaneous Activity of the putamen After Chronic Interruption of The Dopaminergic Pathways. Effect of L-DOPA I= Qharrmacol- Exp. Theres $17 \underline{5}$ $700-708$. 

OLIVIER, A. PARENT, A., SIMARD, H., AND POIRIER, L. J. (1970) Cholinesterasic Striatopallidal And Striatonigral Efferents In The cat And The Monkey Braiㅡㅁ Reseac대, 18 273-282.

OTSUKA, M., KONISKI, S., AND TAKAHASHI, T. (1975) Hypothalamic Substance $P$ As A Candidate For Transmitter of Primary afferent Neurons Fed. 포으르 $3 \underline{4}$ 1922-1928.

PARKINSON, J. (1817) An Essay on The Shaking Palsy, London

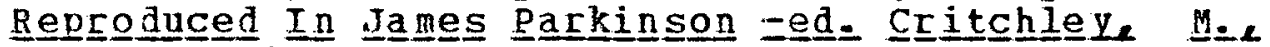

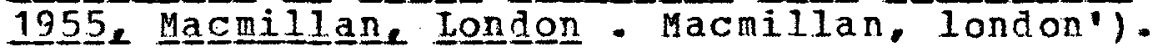

PARNEGGIANI, P. I. (1962) sleep Behaviour Elicited By Electrical stimulation of Cortical And Subcortical

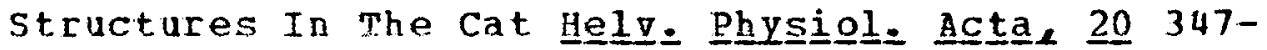
367.

POIRIER, L. J. AND SOURKES, T. L. (1965) Influence of Substantia Nigra on The Catecholamine Content of The Striatum. Brain, $\underline{8} 8$ 181-192.
POIRIER, L. J., MCGEER, E. G., LAROCHELLE, L., MCGEER, P. L. BEDARD, P., AND BOUCHER, R. (1969) The Effect of Brain Stem Lesions on Tyrosine And Tryptophan Hydroxylases In Various structures of The Telencephalon of The Cat B드므므 Research, 14 147- 155.

POIRIER, L. J., SINGE, P., BOUCHER, R., BOUVIER, G., OLIVIER, A. AND LAROCHELLE, P. (1967) Effect of Brain Lesions on Striatal Monoamines In The Cat

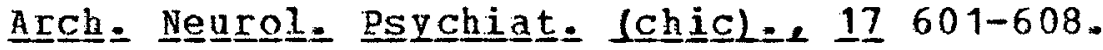

POMPERANO, O. AND BRODAL, A. (1957) Experimental Demonstration of A Somatotopical origin of Rubrospinal Fibres In The cat $\underline{J}=$ Comp. Neuroles 1을 225-251.

PORTIG, P. J. AND VOGT, H. (1969) Release Into The Cerebral Ventricles of Substances With possible Transmitter Function In The Caudate Nucleus J.

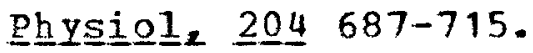


POEELL, T. P. S., AND COWAN, H. M. (1956) A Study of Thalamo-striatal Relations In The Monkey Braiㅡ. 79 364-391.

RANSON, S. W. AND RANSON, S. W., JR. (1942) Efferent Fibers of The Corpus Striatum A. Res. Nerv. And

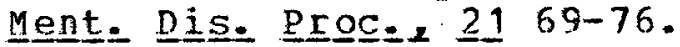

RICHARDSON, T. L., MTLLER, J. J., MCLENNAN, H. (1977) Mechanisms of Excitiation And Inhibition In The Nigrostriatal System. B드므므 Research. 12ㄱ 219-234.

PORPURA, D. P. AND YAHR, H. (EDS.) (1966) The Tha lamus Collumbia Uni

RINVIK, E. AND HALBERG, F. (1963) Demonstration of A Somatotopically Arranged Cortico-rubral Projection In The cat. An Experimental study Hith silver

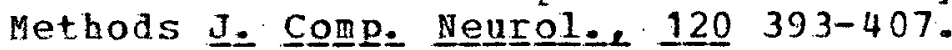

RUSSELL, J. R. AND DEMYER, W. (1961) The Quant itative Cortical origin of Pyramidal Axons of Macaca Rhesus Nㅡuㅡ드으의로 11 96-108.

SHIMIZU, N. AND OHNISHI, S. (1973) Demonstration of Nigroneostriatal Tract By Degeneration Silver Method Brain Researc대. 17 133-138.

STERNBERGER, L. A., HABDY, P. H., CUCDLIS, J. J. AND MYER, H. G. (1970) The Unlabelled Antibody Enzyme Method By Immunohistochemistry: Preparation And properties of Soluble Antigen-antibody complex (horseradish peroxidase-antiperoxidase) And Its Use In Identification of Spirochetes. I-

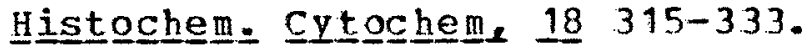

SZABO, J. (1962) Topical Distribution of striatal Efferents In The Monkey Exp. Neuㅡ으료 $\underline{5}$ 21-36.

SZABO, J. (1967) The Efferent Projections of The Putamen In The Monkey Exp. Neuㄷ일 19 463-467. 
TRETIAKOFF, C. (1919) Contribution A L'etude De L'anatomie Pathologique Du Jocus Niger Thesis. Uni paris.

UNGEFSTEDT, U. (1971) Stereotaxic Mapping of The Monoamine Pathways In The Rat Brain Acta. physion. Scande= Suppl= $3 \underline{67} 1-48$.

VOGT, C. AND VOGT, D. (1920) Zur Lehre Der Erkrankungen Des striaren systems $\mathrm{J}$ - Psychol. Neuro으. $2 \underline{5} 627$, 1920.

VONEIDA, T. (1960) An Experimental study of The Course And Destination of Fibers Arising In The Head of the Caudate Nucleus In The Cat And Monkey I. Comp.

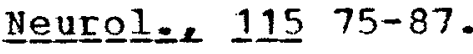

HALBERG，F. (1956) Descending Connections To The Inferior olive. An Experimental Study In The Cat. Nㅡ믐일 10는 $77-173$.

WILSON, S. A. K. (1912) Progressive Lenticular Degeneration; A Familial Nervous Disease Associated ith Cirrhosis of The Liver Brain. 34 295-509.

WILSON, S. A. K. (1914) An Experimental Research Into The Anatomy And Physiology of The corpus striatum Brai‥ $3 \underline{6}$ 427-492.

YORK, D. H. (1975) Amine Receptors In.C.N.S. II. Dopamine In $L$. L. Iversen, S. D. Iversen And S. H. Snyder (eds.) Handbook of psychopharmacology, Vol. $\underline{6}_{2}$

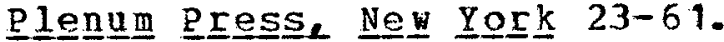

YORK, D. H. (1967) The Inhibitory Action of Dopamine on Neurons of The Caudate Nucleus Brrain Besearch. $\underline{5}$ $263-266$.

YORK, D. H. (1975) Amine Receptors In C.N.S.II Dopamine In $L$. L. Iversen And $S_{\text {. }} H$. Snyder (eds.) Handbook

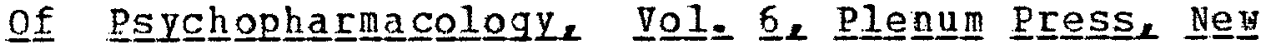
Yok $23-61$. 
YOSHIDA, M. RABIN, A. AND ANDERSON, M. $\begin{array}{r}\text { (1972) } \\ \text { Monosynaptic Inhibition of Pallidal Neurons By }\end{array}$ Axon Collaterals of Caudato-nigral Fibers Exp. Braㅡㄹㅡ Res.2 15 333-347. 


\section{Publications,}

Pearson, J.A. and Richardson, T.L. The influence of stimulus intensity on sensitization of the flexor reflex. Exp. Neuro1. 47, 194-197 (1975).

Richardson, T.L., Miller, J.J. and McLennan, H. Inhibition in the caudate nucleus. Proc. Can. Fed. Biol. Sci. (1975).

Miller, J.J., Richardson, T.L. and McLennan, H. Nigrostriatal inhibition mediated by non-dopaminergic axon collaterals. Proc. Soc. Neurosci. (1975).

Wheal, H.V., Richardson, T.L. and McLennan, H. 3-Dimensional graphics computation as an aid to neuropharmacology. can. Physiol. ㄱ, 65 (1976).

Miller, J.J., Richardson, T.L., Fibiger, H.C. and McLennan, H. Anatomical and electrophysiological identification of a projection from the mesencephalic raphe to the caudateputamen in the rat. Brain Res. 97, 133-138 (1975).

Richardson, T.L., Miller, J.J. and McLennan, H. Mechanisms of excitation and inhibition in the nigrostriatal system. Brain Res. 127, 219-234 (1977).

Ha11, J.G., Hicks, T.P., McLennan, H., Richardson, T.L. and Wheal, H.V. The excitation of mammalian central neurones by amino acids. J. Physiol. 286, 29-39 (1979). 